\title{
Maternal Health Service Delivery in Ghana: A Case Study of Korle-Bu Teaching Hospital
}

\author{
Lilian Kornu* $\quad$ Wilhelmina Ahiaku Seyome Osman Issah Fuseini \\ School of Public Affairs and Administration, University of Electronic Science and Technology of China, P.R. \\ China Address: No.2006,Xiyuan Ave.West Hi-Tech.Zone,P.R.China \\ Post Code: 611731
}

\begin{abstract}
Maternal mortality has become one of the major problems that has plagued the world, particularly in developing countries including Ghana. The overarching objective of this paper is to explore the maternal health service delivery in Ghana. Specifically, the study assessed the performance of service delivery of maternal health care with regards to the MDG 5; examined patients satisfaction with maternal health service delivery; and analyzed the effectiveness and efficiency of maternal health service delivery in Korle-Bu. The Korle-Bu teaching hospital was chosen because it is the major national hospital in Ghana. Secondary data was collected from records of health facilities and primary data from the administration of a questionnaire with key variables that were studied including antenatal and postnatal care. A total sample size of 60 respondents was used in this study and the respondents comprised of women who visited the Korle-Bu teaching hospital for antenatal and post-natal services. The exploration of maternal service was done from two major perspectives, that is, women attitude towards attending antenatal care and post-natal care and the services provided by health care professionals towards achieving effective and efficient results. This approach was adopted because curbing maternal mortality is linked to attending proper and regular antenatal care.

The study revealed that antenatal care related negatively with maternal mortality whiles post-natal care related positively to maternal mortality. Findings also indicated that education of the public about the maternal health policy will help reduce the misconceptions and misunderstandings presented by the introduction of the policy. The paper argues from the findings that most women remained unaware about certain features of the maternal health policy. Thus, they encounter several problems due to this situation and it however delays childbirth. Findings also indicated that there is a positive relationship between the services provided by the health service personnel's and the level of satisfaction that the women receive about the services provided to them. The findings of this paper also indicated that, in as much as Ghana has introduced several measures to help the country reduce the maternal mortality rate, there exist several shortfalls in its maternal health service delivery system. These shortfalls as indicated above hinder the efficient and effective delivery of better services offered to pregnant women. Thus, the study recommended the implementation of proper measures and mechanism in the policy that will help curtail the high rate of maternal mortality in the country and help the country achieve the MDG target set by the United Nations.
\end{abstract}

Keywords: Maternal Health, Maternal Health system, Maternal Mortality

DOI: $10.7176 /$ PPAR/9-4-11

Publication date: April $30^{\text {th }} 2019$

\subsection{Introduction}

Health systems worldwide fail to provide and produce optimal health outcome, and successive reforms and changes have sought to make them more efficient, effective, more equitable and more responsive. According to Lannes (2015), the main influx of these changes was the establishment of national medicinal services frameworks and social protection frameworks. However, these changes just occurred in high income countries (HIC). The second wave energized and centered essential human services administrations to guarantee practical, evenhanded and available health system administration. As of late, health system frameworks have enhanced quickly. World life expectancy rose from 25 to 65 years for men and to 70 years for ladies in two centuries (Lannes, 2015). This rise can exclusively be ascribed to the enhancements of wellbeing frameworks and as such reduce mortality and dismalness. The World Health Organization (2010) underscored that a health system framework that is working well reacts in a balanced way to a population's needs and desire by: enhancing the health status of people, families and groups, safeguarding the populace against what debilitates its health, ensuring individuals against the monetary outcomes of sick health, giving impartial access to individuals focused care, making it feasible for individuals to take an interest in choices.

Maternal health is an issue of paramount importance to countries most especially developing countries. Developing countries continue to bear the larger portion of pregnancy-related deaths. It is recognized that the 
access to skilled delivery care of good quality will contribute to reducing maternal and perinatal mortality and morbidity. Maternal health however goes beyond the survival of pregnant women and mothers. For every woman who dies from the causes related to pregnancy or childbirth, it is estimated that there are 20 others who suffer pregnancy related-illness or experience other severe consequences. The number is striking, an estimated 10 million women annually who survive their pregnancies experience such adverse outcomes. Maternal mortality is a prevalent problem particularly in nations that are developing which includes Ghana and as a result this has led to an increase in the United Nations agency for health, World Health Organization developing a millennium development goal plan that will help reduce maternal health problems by 2015 . The two targets for assessing this Millennium Development Goal (MDG) 5 are reducing the maternal mortality ratio (MMR) by three quarters between 1990 and 2015 levels and achieving universal access to reproductive health by 2015 .

\subsection{Problem Statement}

Despite the number of deaths recorded as a result of maternal mortality, there are still some shortfalls when it comes to maternal health service delivery. Numerous attempts have been undertaken by the Ghanaian government to reduce the level of maternal mortality ratio. According to the Ghana medical journal (2003), the Ministry of Health of Ghana introduced an exemption maternal health policy directed at making child delivery free. The thrust of these policies has been to improve uptake, quality and financial and geographic access to delivery care services.

A report by the Overseas Development Institute (ODI) in 2012 states that, there are common obstacles to the effective delivery of proper maternal health service delivery in Africa. And these obstacles act as bottlenecks that prevent the provision of effective maternal health service delivery and are often prevalent in the rural settings.

Ghana as a nation has recorded several maternal mortality issues. According to WHO/UNICEF (1996) globally some 585,000 women die annually from pregnancy - related complications. WHO/UNICEF estimated Ghana's rate to be 740 per 100,000 live births while the Ministry of Health calculates this to be 214 per 1,000 live births. As to be expected, there are regional variations.

Studies conducted by Gumanga et al. (2011) at the Tamale Teaching Hospital, over a 5-year period, that is, from 2006-2010, the maternal mortality ratio was 1018.7 , per 100,000 live births, or a total of 280 deaths. These statistics are quite worrisome in view of how far away it is from the MDG target of 185 per 100,000 by 2015 . Experts argue that at current pace, Ghana may not be able to realize the MDGs in relation to maternal and child health by the year 2015 if there will not be an urgent redrafting of policy and the operational strategies with the view to reposition maternal child health promotion issues in Ghana (Yamikeh, 2008).

It could be inferred from the above analysis that in as much as Ghana has made steady progress in its quest to improve maternal health service delivery in the country by introducing policy's and taking various actions to combat and improve the health status of its citizens, the government still falls short in improving upon its maternal health related cases. The measures, the solutions and the strategic ways of improving maternal health service delivery in Ghana has not yielded any progressive reports, therefore there is the need to study and make recommendations to help improve this sector. It is in this direction that this research work to actually illuminate the issues regarding maternal health service delivery in Ghana.

\subsection{Research Objectives}

The main aim of the research was to examine maternal health service delivery in Korle-Bu Teaching hospital. In line with this, the study specifically:

1. assessed the performance of service delivery of maternal health care at Korle-Bu with regards to the MDG 5,

2. examined patients satisfaction with maternal health service delivery at Korle-Bu, and

3. analyzed the effectiveness and efficiency of maternal health service delivery in Korle-Bu.

\subsection{Research Questions}

The following research questions were formulated to achieve the stated study objectives.

1. Has the maternal health service delivery at Korle-Bu met the MDG 5?

2. Are patients satisfied with the maternal health service delivery received at Korle-Bu?

3. How effective and efficient is the maternal health service delivery in Korle-Bu? 
4. Does the health system provide any form of maternal education to women in general in Ghana?

\subsection{Research Significance}

Ghana is not the only country plagued by the issue of maternal mortality. Several statistics indicates that low income countries record the highest form of maternal mortality. This study identified the fundamental issues in maternal health service delivery in Ghana and the challenges that impede the effective and efficient administration of the service. The findings of this study raised some potential inputs into the enhancement of the implementation strategy of the maternal health policy. The study stated that there is the need for government to invest more in educating the public about the maternal health policy, its aims, and objectives and why it was established. In addition, the maternal health policy should develop a system that will attribute pay to performance. Furthermore, the maternal health policy alone cannot help reduce maternal mortality without taking other equally important factors into considerations. Thus, there is the need to improve upon the infrastructure of most of the hospitals across the nation. Lastly, this research work asserted that the government should invest more in capacity building programmes to enable all the parties involved improve their skills and knowledge needed to do their jobs effectively. This capacity building programmes should not only be focused on educating women but also doctors, midwives, nurses and other stakeholders involved in the policy formulation Women and unborn babies are however relevant resources to every country and the society as a whole. Thus, it is vital to protect them and ensure that they are safe. Improving maternal health service delivery will however cut down the rate of dates recorded during birth, at birth and even after birth.

\subsection{Conceptual Framework}

This part of the study dealt with the conceptual framework. Thus the researcher tried to evaluate the maternal health service delivery in Ghana and asses the maternal health services delivery in terms of service indicators. The current effectiveness and efficiency were evaluated and this helped to describe the situation and problems associated with maternal health service delivery so as to make recommendations to improve the maternal health service delivery at Korle-Bu.

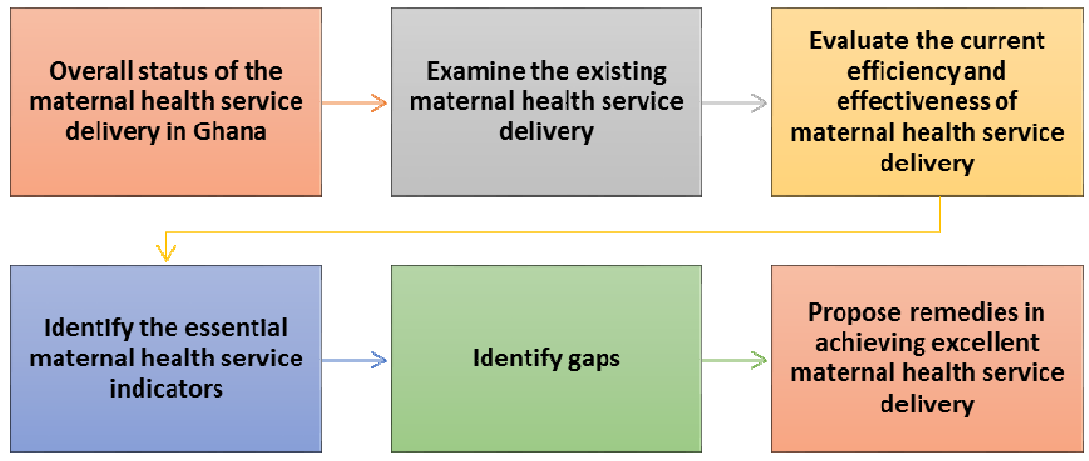

Figure 1: Conceptual Framework

\subsection{Research Methodology \\ 2.1 Research Area}

This research is rooted in the health sector in Ghana. The health sector is one of the most important sectors that usually need to be given much attention to by every government. Failure to improve upon the health sector will definitely lead to many unwanted circumstances and primary among them is death. Therefore, this study was directed towards issues relating to maternal health service delivery in Ghana. Specifically, issues pertaining to antenatal care, postnatal care, delivery care and the consequences of maternal mortality were addressed in this study.

\subsection{Sources of Data}

Data for this research work was gathered from two main sources. The researcher relied on both primary source of data and secondary source of data. Primary data was gathered from respondents who have been receiving maternal health service delivery from the Korle-Bu teaching hospital. Important and relevant information was 
gathered from the clients regarding the maternal health service delivery they receive at the Korle-Bu teaching hospital. Secondary data was gathered by relying on previous studies done in this research area.

\subsection{Target Population and Sample Size}

The targeted population of the study was women who receive care under the maternal health service system at Korle-Bu Teaching Hospital. The sample size for this study was sixty (60).

\subsection{Data Instrument and Sampling Technique}

The sampling technique used in this research study was the simple random sampling technique. The instruments used in collecting the data were both interviews and questionnaires. The interviews on the other hand were structured interviews.

This study used the simple random sampling method. According to Ahmed (2009), in a simple random sample each element has an equal probability of being selected from a list of all population units (sample of $\mathrm{n}$ from $\mathrm{N}$ population).

\subsection{Data Analysis Mode and Techniques}

Data collected and gathered during the study was analyzed and interpreted to give meaning to the study. Descriptive analysis were however conducted to generate graphs, charts and tables to explain and answer the research questions based on the information gathered.

The statistical tools used for the data processing were excel sheet, Statistical Package for Social Science version 22.

\subsection{Literature Review}

This chapter of the study introduced key concepts used in the study, related theories used in this study and literature reviews on maternal health service delivery in Ghana and abroad.

\subsection{Maternal Health}

The World Health Organization report (2008), views maternal health as the health of women during pregnancy, childbirth and the postpartum period. While parenthood is frequently a positive and satisfying background, for an excessive number of women it is related with agony, sick wellbeing and even death. The major, direct reasons for maternal morbidity and mortality includes: infection, high blood pressure, unsafe abortion and premature birth. Therefore, in order to help reduce the rate of maternal mortality and morbidity, there is the need to take into consideration vital measures such as family planning, preconception, and antenatal and post-natal care.

\subsection{Maternal Health Service Delivery}

The World Health Organization (2008) views maternal health service as the service provision or delivery of an immediate output of the inputs into the health system, such as the health workforce, procurement and supplies, and financing. Increased inputs should lead to improved service delivery and enhanced access to services. Therefore, increased inputs into maternal health service delivery will lead to improved service delivery and enhance access to services. Maternal health service delivery however, falls under the broad spectrum of health service delivery. This means, it requires specific efforts aimed at strengthening service delivery to help achieve the health-related goal of the Millennium Development Goal that includes the delivery of measures to help curb child mortality and maternal mortality WHO(2008)

The WHO further states that, the delivery of services is made up of several interdependent, interrelated and interconnected inputs and outputs into the health system. Thus, frequent and effective service delivery will lead to a proper health system.

\subsection{Maternal Health System}

Von Bertalanffy (1968) states that a "system" can be comprehended as an arrangement of various parts and their interconnections that come together for a specific reason. In this way from the above clarification, it could be comprehended that maternal health system is the courses of action of different segments that meet up to work with the end goal of enhancing maternal social insurance.

Most nations have a structure for a system that observes and monitors the general health care of the population living in that nation and in this manner maternal well-being framework falls under health systems. 


\subsection{Literature Review on Maternal Health Service Delivery in Ghana}

Governments all over the world have invested in strategies that will help address the issues of maternal deaths through the establishment and implementation of policies, legislations and services. Ghana accepted the Safe Mother-hood Initiative that was introduced in the year 1987 by the following agencies. Also, free antenatal care was introduced to all pregnant women in the year 1988 and in September 2003, a policy was introduced that exempted all users from delivery fees in health facilities. Thus, this implied that the barriers that impeded women's ability to use antenatal and delivery care in both the public and private health hospitals have been removed.

According to the Ghana Medical Journal, this was geared towards complimenting the role of dedicated and skilled health professionals to achieve a reduction in the maternal mortality rate (Ghana Medical Journal, 2006). In as much as maternal health care has improved over the past years, the rate has been at a slow pace and extra effort is needed for Ghana to be able to achieve the MDG 5 target which seeks to reduce maternal mortality rate by three quarters by the year 2015. According to the Ghana health service, "institutional maternal mortality rate has reduced from 216 per 100,000 live births in 1990 to 164 per 100,000 live births in 2010 with a distance of 110 to target of 54 per 100,000 in 2015. The full implementation of the recently developed MDG Acceleration Framework (MAF) gives hope that MMR will further reduce by 2015 (www.ghanahealthservice.org). According to the Ghana Health Service, a number of interventions introduced by government to improve maternal healthcare include the following: the implementation of free maternal health services, repositioning family planning and training as well as repositioning reproductive and child health staff; a safe motherhood task force is operational and government is supporting increased production of midwives through direct midwifery training; the High Impact Rapid Delivery (HIRD) approach is also being implemented as a complementary strategy to reduce maternal and child mortality. Several districts have indicated progress in service indicators achieved and innovative strategies implemented with regard to improving maternal health; other interventions also include Ghana VAST Survival Programme, Prevention of Maternal Mortality Programme (PMMP), and Safe-Motherhood Initiative; there are also projects such as Making Pregnancy Safer Initiative, Prevention and Management of Safe Abortion Programme, Maternal and Neonatal Health Programme and Roll Back Malaria Programme, Intermittent Preventive Treatment (IPT); and emergency Obstetric and Neonatal Care (EmONC) is being implemented in all 10 regions, but not yet with full complement of required resources (midwives, equipment).

To further avoid maternal deaths or its occurrence, all Ghanaian societies put across elaborate dietary and behavioral codes for expectant women in order to ensure not only safe delivery but also the delivery of normal children (Senah, 2003). Some of the codes include what a woman must wear not to expose her stomach or navel; a woman should not buy food from outside or eat in public. Although all these measures are put in place to avoid maternal deaths, the WHO/UNICEF estimate Ghana's rate of pregnancy related complications to be 740 per 100,000 live births while Ghana's Ministry of Health calculates this to be 214 per 1,000 live births (Senah, 2003). Witter et al (2009) also affirmed, Ghana persistently high maternal mortality ratios, estimating the range from 214 to 800 per 100,000 live births. Although these figure points to the total maternal related deaths of Ghana, there are regional variations (senah, 2003). There are growing social inequalities, with rates of skilled attendance either stagnant or declining for poorer women. The three northern regions of the country have the highest levels of poverty and maternal mortality and the lowest levels of supervised deliveries(Witter et al 2009) as cited in Ameyaw (2011). While deliveries with health professionals rose from 85\% to 90\% from 1993 to 2003 for the richest quintile, according to Demographic and Health Survey data, deliveries with health professionals for the poorest quintile dropped from $25 \%$ to $19 \%$. Nationally, $45 \%$ of births were attended by a medical practitioner $(79 \%$ in urban areas, $33 \%$ in rural); $31 \%$ by traditional birth attendants (TBAs) and $25 \%$ were unsupervised.

In Ghana's health system, basic obstetric and antenatal care is provided by health centers, health posts, mission clinics and private midwifery homes. Each health centre or post serves a population of approximately 20,000 (Witter et al, 2009). In the rural areas, TBAs continue to carry out deliveries, though they are trained to refer more complex cases. Comprehensive emergency obstetric care is available in district hospitals and regional hospitals, as well as national referral hospitals. Most are run by the Ghana Health Services, though the mission sector plays a significant role, especially in more remote regions. All care is paid for, unless the service is exempt or the person has private or public health insurance, though user fees are subsidized by public inputs into the services (Witter et al, 2009). 
Financial barriers are believed to be one of the most important constraints to seeking skilled care during delivery in Ghana. A study costing maternal health care in one district in 1999 found cost recovery rates between $152 \%$ for deliveries and $211 \%$ for caesareans in mission hospitals, but did not shed light on affordability relative to women's income (Witter et al, 2009). Problems such as under-funding of exemptions from user fees in general have also been found, which have meant that exemptions are available in theory but not always in practice if the provider is not reimbursed for lost income (Witter, Arhinful, Kusi, \& Zakariah-Akoto, 2007).

A research conducted by the Navrongo Health Research Centre shows that the government's free maternal health care policy is not working in the Upper East region. The free maternal health care policy which begun in Ghana in 2008 is being implemented through the National Health Insurance Scheme (NHIS) aimed at facilitating access to free quality maternal health care services such as antenatal, delivery and postnatal care at health facilities, (ghanabusinessnews.com).

The research funded by the Presbyterian Health Service-North, was done because of public outcry that pregnant women in many health facilities were charged for health services during antenatal, delivery and postnatal care. It revealed that women who attended some of the health facilities were compelled to buy medicine including antibiotics, blood tonic and pay for laboratory and scan tests either in the health facilities or outside the facilities as well as buy disinfectants, bed spread, sanitary pads and soap in preparation for delivery. The research indicated that such hidden cost of seeking maternal care did not only discourage many pregnant women from going to health facilities to deliver but also led to maternal and infant deaths. It attributed the problem mainly to the non-availability or shortage of medicines, laboratory reagents and ultrasound machine at the health facilities, (ghanabusinessnews.com).

The research also identified unreliable phone lines, inadequate and high cost of ambulance services, lack of spare parts and inadequate fuel for ambulance services as some of the challenges. The Free Maternal Health Care Initiative provides subsidized health insurance to pregnant women, giving them access to an existing range of insurance benefits that includes comprehensive maternity care with some notable exceptions such as ambulance service and post-partum family planning counseling. It is supported from the general pool of resources of the National Health Insurance Fund, which includes contributions from international partners via the health sector budget support. The evaluation of the free maternal health care initiative in Ghana follows almost five years after it was launched in 2008.

The main objectives of the evaluation were: to evaluate the impact of the Ministry of Health's free maternal health care policy on utilization of skilled delivery services in Ghana; and to evaluate the impact of the free maternal health care policy on quality of maternal health services, (unicef.org). Since inception of the initiative in 2008, there has been a steady increase in the number of facility-based deliveries from about 300,000 in 2007 to about 500,000 in 2011 . The utilization rate reported by the Ghana

Health Service in 2011 was about $66 \%$ which is confirmed by population-based data of the 2011 Multiple Indicator Cluster Survey. The institutional maternal mortality ratio reported by the Ghana Health Service declined from 230 per 100,000 in 2007 to 170 in 2011 . The 21 hospitals sampled were making an effort to cope with the growing number of maternity clients. Their main constraint was a severe shortage of human resources. The majority of hospitals faced challenges in providing an acceptable level of privacy and confidentiality for women during delivery. The referral system was affected by shortages and/or user fees for ambulance services. Supervision was not well documented and not conducted with the expected frequency.

Just like other developing countries, deaths recorded during pregnancy and childbirth is often attributed to the three delays and they include: delays in the home, delays in accessing the health facility and delays at the health facility. According to GHS (2006) report, the first delay occurs when pregnant women contemplate over the issue of seeking care. The report points out that this problem can be linked to the lack of information and inadequate knowledge about responding to initial warning signs of complications of pregnancy and danger signals during labor. The report also explains that some traditions, beliefs and cultures in the country mandates women to seek for approval from the male relatives before seeking medical help (GHS, 2006). The second delay is linked to the problems faced by women in accessing health facilities. Weak referral linkages as pointed out exist between community, health centers and district hospitals making it difficult for women in emergency situations to get the care they need (GHS, 2006). 
The situation as mentioned above is usually worsened due to poor roads and communication networks, distant health facilities, and a lack of transportation and inadequate community support (GHS, 2006). The third delay as identified by the Ghana Health Service occurs between the time the woman arrives at the health facility and the facilities response in providing appropriate care. The findings indicates that health centers preparedness to respond to obstetric emergencies is generally inadequate in terms of skilled attendants, equipment, supplies and drugs, and motivated staff (GHS, 2006).

\subsection{Literature Review on Maternal Health Service Delivery Abroad}

Across the globe, the health of women who are in the reproductive age group has drawn much attention of all governments especially in the developing countries where maternal mortality proportions go from 200 to 800 passing's for each 100,000 live births. In spite of the fact that women in the reproductive age form about around $22 \%$ of the populace in most developing nations, they convey the weight of pregnancy, labor and youngster mind and along these lines shape an uncommon helpless gathering (Ghana Medical Journal 2006).

Maternal health has emerged as global priority because of a great gap in the status of mother's well-being between the rich and the poor countries. According to UN (2008) maternal health refers to the health of women during pregnancy, childbirth and the postpartum period. In rich nations, where women have access to basic health care, giving birth is a positive and fulfilling experience. On the other hand, for many women in poor countries it is associated with suffering, ill health and even death.

WHO (2008) report defines maternal health as the health of women during pregnancy, childbirth and the postpartum period. However, Sari (2009) argues that increasing attention given to maternal health internationally has been concentrated in reducing maternal mortality. However, global attention on the phenomenon of maternal mortality had been given little or no place until two decades ago. Awareness on maternal mortality began to be more serious in the 1980's but more precisely 1985 when, Rosenfield and Maine published a thought-provoking article in the Lancet (Senah, 2003). In their article titled 'Maternal

Mortality - a neglected tragedy — where is the M in MCH?' Rosenfield and Maine warned the world of the fact that many countries were neglecting this important problem and that existing programs were unlikely to reduce the high maternal mortality rates (Senah, 2003). Immediately after this awareness, many authors went out to find out more. Harrison's (1985) analysis of 22,774 consecutive hospital births in Zaria (Northern Nigeria) also gave way to the appalling mortality associated with childbirth. This was followed by another significant input to the campaign against maternal deaths by the World Health Organization's (1986) publication, 'Maternal Mortality: helping women off the road to death'.

This continuous campaign further led to the Safe Motherhood Conference in Nairobi, Kenya in 1987 where speakers presented global statistics on death and complications resulting from pregnancy. The conference concluded with strong recommendations about maternal health and the need to address them. Improving maternal health and reducing maternal mortality since then have been key concerns of global conferences and forums convened during the last two decades, including the 1994 Cairo ICPD and the 2000 Millennium Summit (Farah \& Rasheed, 2009; United Nations General Assembly, 2000; UN, 1994). Many development organizations have been implementing various programs related to reproductive and maternal health most of which have been implemented in partnership with government line ministry (United Nations Economic and Social Commission for Asia and the Pacific, 2008), as cited in Ameyaw (2011).

One of the Goals which guided the ICPD was : "to promote women's health and safe motherhood; to achieve a rapid and substantial reduction in maternal morbidity and mortality and reduce the differences observed between developing and developed countries and within countries. On the basis of a commitment to women's health and well-being, to reduce greatly the number of deaths and morbidity from unsafe abortion; to improve the health and nutritional status of women, especially of pregnant and nursing women" (Farah \& Rasheed, 2009).

Internationally, increasing attention given to maternal health has been concentrated in reducing maternal mortality. The tragedy of not preventing these avoidable or treatable deaths resulted in 536,000 maternal deaths worldwide in 2005 (WHO, 2006). Developing regions accounted for 99 percent $(533,000)$ of these deaths, with sub-Saharan Africa and Southern Asia accounting for 86 percent of them (UN, 2008). Millions more women 
survive but suffer from illness and disability related to pregnancy and two childbirths. It has been estimated by the Safe Motherhood Initiative (SMI) that 30 to 50 morbidities occur for each maternal death (Shiffman, 2003).

In this contemporary world, maternal mortality is regarded as a violation of the rights of women. The rate of occurrence or prevalence of the phenomenon is thus perceived as a critical index of the level of development of a country. Accordingly to meet this critical level of development, nations all over the world have instituted programs and policies within their available resources to combat this menace (Senah, 2003). There have been high government (political) and organizational commitments to halt this widely-recognized women's right violation. Farah \& Rasheed (2009) asserted that regardless of continued high-level political and organizational commitments, maternal mortality remains as one of the greatest challenges facing the developing world, as well as a tragedy that has often been neglected or compromised. To them the progress on the maternal mortality reduction target has been far too slow to reach the set goal, a sad reality that many view as one of most embarrassing manifestation of health and social systems failure, (Ameyaw 2011).

Others however argue this is due to the notoriously difficult means of measuring accurately the maternal levels in developing countries (Farah and Rasheed 2009; the United Nations Economic and Social Commission for Asia and the Pacific 2008; Senah 2003). A country, measurements of the maternal mortality ratio (MMR) is further suffered from under reporting and variance in methodologies. The United Nations Economic and Social Commission for Asia and The Pacific (2008) indicate although comprehensive and accurate estimate of MMR requires systematic vital registration, longitudinal studies of pregnant women and household surveys, the vital registration system in Nepal has a limited coverage while national level survey especially focusing on estimating maternal mortality does not exist. Major and important reports, such as MDG Progress Report and Human Development Report are accused of using various sources of data having different sample size and methodologies to compare MMR data over a period of time (The United Nations Economic and Social Commission for Asia and the Pacific 2008).

In the views of Farah and Rasheed (2009), these are due to the inefficiencies within the civil registration systems, lack of knowledge of the pregnancy status of the deceased, in addition to inaccurate medical certification of the cause of death(Farah \& Rasheed, 2009). Senah (2003) corroborates this stating maternal mortality figures globally are fraught with a number of problems due to the fact that: all deaths of women of reproductive age (15-46 years) and the cause of deaths are not known, few countries count birth and death and even fewer register the cause of death, and it cannot be determined whether or not the woman was pregnant at the time of death or had recently been so. Farah and Rasheed (2009) argue that even in developed countries, the information on maternal death may be missing, misclassified (direct or indirect causes; accidental or incidental) or underreported.

WHO has summarized three crucial factors underlying maternal deaths. Firstly, lack of access and utilization of essential obstetric services. There is a negative association between maternal mortality rates and maternal health care utilization. WHO estimates suggest that 88 to 98 percent of all pregnancy-related deaths are avoidable if all women would have access to effective reproductive health care services (Shiffman, 2003). Secondly is the low social status of women in developing countries. The low status of women can limit their access to economic resources and basic education, the impact is that they have limited ability to make decisions, including a decision related to their health and nutrition. Thirdly, too much physical work together with poor diet also contributes to poor maternal health outcomes.

The effects of maternal health care (or access to care) on subsequent wellbeing and mortality risks in the early infant period has particularly been documented in previous Indian studies (Thaver\&Bhutta, 2006). The further findings are that the health seeking behavior of individuals and family is critical in determining maternal and child morbidity and mortality. Care seeking behavior has been strongly associated with such factors determining maternal and child health (Ramasubban \& Singh, 1999). In essence, the outcome variables on the issues of maternal and child health status will be a function of the consideration of the cumulative effects of use versus nonuse of antenatal care. Women who receive too few antenatal care visits timed in appropriately within their pregnancies can be identified and the risk factors associated with these modeled, in maternal health care indicators (Park \& Park, 1989).

The WHO (1992) estimates that 88-98\% of pregnancy-related deaths are avoidable. The affirmed stance of Kausar, Griffiths, and Matthews (1999) is that women who receive some form of schooling also have higher 
probability of using antenatal care services and have relatively lower risks of experiencing maternal deaths, and deaths of their infants and children, than their illiterate counterparts. The issues of whether poverty impacts directly on quality of maternal and child health; whether poor maternal and child health invariably compounds poverty situation; and the intricacy of these variables remain critically situational, as cited in Abu-Hassan (2011).

Reports indicate about 500,000 and over women the world over die yearly from pregnancy related complications. WHO/UNICEF (1996) state some 585,000 women globally die yearly from pregnancy - related problems. A more recent report by the WHO (2007) also posit an estimated total of 536,000 maternal deaths worldwide. Of these figures an estimated 99 percent of such women are reported to come from the developing world, especially sub-Saharan Africa (Farah \& Rasheed, 2009; WHO, 2007; Senah, 2003) revealing huge global differences and inequalities. Sub-Saharan Africa and Asia accounted for 86 percent of this figure (Farah \& Rasheed, 2009; UN, 2008). This disproportion in countries is also made eminent in the UNICEF et al report which asserts of the average lifetime risk of maternal death of 1 in 76 in the developing world, there is a 1 in 8000 in the industrialized countries. This is affirmed by Filippi et al (2006) as cited in Ameyaw (2011) who assert in sub-Saharan Africa, 1 in 16 women dies in pregnancy or from childbirth a risk 175 times higher than that in developed countries (1 in 2,800). To Sari (2009), maternal health has emerged as global priority because of a great gap in the status of mother's well-being between the rich and the poor countries.

To Farah and Rasheed (2009), this disparity becomes even more frightening when cross-country comparisons of the lifetime risk are taken into account. For instance, in out of 1 in 47,600 in Ireland, there is 1 in 7 in Niger women dying in pregnancy or from childbirth. Filippi et al (2006) further pointed out that the world's stipulated 500,000 and over maternal deaths but that is just the tip of the iceberg, as many more women are estimated to suffer pregnancy-related illnesses (9.5 million), near-miss events ( 1.4 million), and other potentially devastating consequences after birth (Filippi et al, 2006), as cited in Ameyaw (2011).

\subsection{Research Related Theories} 3.6.1 Gender and Development Theory

Gender inequality exists in any general public and adds to the subordination of women in respect to men in many settings. Gendered structures put obstructions to women access to paid work, training and health services which could furnish them with life-sparing consideration. These sex standards and structures are in this manner significant to any analysis of maternal health (Hagman 2013).

The part women are given in the public arena is of critical significance to gender orientation imbalances. Women have an expansive impact in the organization and creation of the family, yet their contribution in pursued work outside the family is restricted. Women are along these lines seen as the housewives and homemakers, limited to the private circle while men command the general population circle and partake in profitable work outside the home (Moser 1993). This division of work is tricky as it gives the man full control over all pay creating work and subsequently likewise over the assets delivered. Women hence tend to depend and rely on men in getting to assets, even such basic choices as acquiring family unit things will be made by the man (Allen, 1999).

However, the fact that women often are confined to the private sphere does not necessarily mean that they only undertake reproductive housework. They may also function as secondary income earners, although this work is often undertaken in the home or immediate neighborhood meaning that they still remain in the private. Community management is also often performed by women; however the leadership roles are still reserved for men again reflecting the gendered division of labor, (Hagman 2013). These different roles, which Moser calls 'the triple role of women', mean that the workload of women is often quite diverse and this is an important factor to consider when assessing women's position in any community (Moser 1989: 1801).

Nevertheless, despite these triple roles women are often viewed primarily as child bearers, their principal duty being to reproduce. This reproductive role comes of importance from a quite early age and also contributes to the low education and literacy levels of many women (Stromquist, 1990).

Women's duty as the housewife and organizer of the household in combination with the reproductive role pose further problems to women's health. Because pregnancy is seen as the 'normal' state, not a as a condition requiring care as it is not an illness, women are discouraged from seeking professional care as they and the 
community believe that they do not need it. The triple role and the amount of work women do often goes unseen by the community as it is perceived as being non-productive.

Consequently, the fact that the heavy workload can have implications for women's health and wellbeing may be ignored by both the women themselves and society at large. Additionally, the threshold of illness recognized by society is very high for women and many women will endure a lot of pain before seeking care as they cannot afford to disrupt the household organization which they have the primary responsibility for (Okojie, 1994). The lack of education and information available to women further increases this problem as they will not be able to read the 'danger signs' and hence delay seeking medical care.

Because of the emphasis on fertility and reproduction, the female body becomes central to women's subordination. Women's bodies become their primary resource that can determine their social status in terms of reproduction as well as sexual availability. Also, adolescent girls experience the pressure to be sexually active and available to their partners. A girl's respectability is dependent on her being sexually available and allowing her partner sexual decision-making authority (Varga, 2003). Furthermore, women's lack of decision making power when it comes to the use of contraceptives further undermines the status of women as they may be forced to engage in risky sexual behavior to retain respectability.

Unprotected sex may then lead to unwanted pregnancies which can pose a threat to the woman's health. Societies dominated by patriarchal structures pose a great barrier to women's empowerment. The structural relationships of power between males and females, where men hold the superior position cause a loss of freedom for women and may also increase the risk of violence against women (Bunch, 1990). According to Einspahr patriarchy is a structure of domination, where the relationship between men and women need to be considered in terms of their relative position as members of a group. Thus, power relations and domination focuses "on the ability of some groups to systematically interfere in the lives of other groups, whether or not such power is exercised by all individuals so capable, as cited by Hagman (2013). It is therefore important to recognize the differences between women and the intersections like class, race and age when discussing their role in a patriarchal society. Not all women are oppressed by men and some women have power over other women, or over men. However, as members of a group women face greater interference in their lives by men, compared to the ability women have to interfere in the lives of men. The individual woman may not face subordination by an individual male but nevertheless the freedom of women is hindered by the systematic domination by men in society.

Women's access to education is crucial if female empowerment is ever to be achieved.

Education is an important tool that can be used to give women more power, improve gender equity and consequently also women's health. Research by McTavish et al. in sub-Saharan Africa showed that mothers in countries with higher female literacy rates are more likely to use maternal health care than women living in countries where national levels of female literacy are low (Bunch,1990). Furthermore, higher educated women will also have greater personal safety and access to resources and labor markets which may give them a greater freedom. Gender discrimination with regards to education often starts from childhood, where boys are given primary access to education. This problem links in to the role women have in society. As they are primarily viewed as child bearers and wives, society finds it unnecessary to invest money and resources into a girl's education as she will not engage in any waged labor and the money invested will therefore not generate any return to the family (Okojie 1994). For boys, on the other hand, education is seen as an investment that will increase the likelihood of them obtaining higher-waged work later. Consequently, the gendered division of labor reinforces the discrimination of girls. If women would have more access to paid work the likelihood of families investing in their education would be higher as the girl would be able to pay back some of the money and support her parents when they get old. Because of this lack of education for girls, they often grow up to be illiterate hence further increasing their dependence on their husbands or other males for access to information (Sesay, 2010). A woman with none, or little, education will be less inclined to seek health care as she will lack the necessary information on how to access it or. Furthermore, rumors and prejudice regarding medical personnel and their treatment of pregnant women will also be more easily spread among uneducated women who do not have access to the needed and vital information. When the status of women is high, they are more likely to have access to education and hence information, and will therefore be more inclined to seek care and to 
choose trained medical personnel over traditional birth attendants (Erdman, 2012). Low levels of education therefore make women extremely vulnerable and dependent and pose a very real threat to women's health. Although education is vital to equip girls with the knowledge necessary to reduce gender gaps, this will not be achieved until the schooling they receive is gender neutral. Without a gender sensitive curriculum girls will not be able to reach their full potential (Leach 1998$)^{[26]}$ and their access to other services such as health care and abortion, will remain limited.

\subsubsection{Scientific Management Theory}

Frederick W. Taylor's scientific theory hypopaper tries to enhance an association's proficiency by systematically enhancing the productivity of assignment culmination by using logical, building, and scientific investigation. The objective is to diminish waste, increment the procedure and techniques for generation, and make a just circulation of products. This objective serves the basic interests of managers, representatives, and society.Scientific management, or Taylorism, is a management theory that analyzes work flows to improve economic efficiency, especially labor productivity. This management theory, developed by Frederick Winslow Taylor, was popular in the 1880 s and 1890 s in manufacturing industries.

While the terms "scientific management" and "Taylorism" are often treated as synonymous, an alternative view considers Taylorism to be the first form of scientific management. Taylorism is sometimes called the "classical perspective," meaning that it is still observed for its influence but no longer practiced exclusively. Scientific management was best known from 1910 to 1920, but in the 1920s, competing management theories and methods emerged, rendering scientific management largely obsolete by the 1930s. However, many of the themes of scientific management are still seen in industrial engineering and management today.

In this modern society, a classic example of the scientific management theory would be determining the amount of time it takes workers to complete a specific task and determining ways to decrease this amount of time by eliminating any potential waste in the workers' process. A significant characteristic of this theory was time studies. Taylor was concerned with reducing process time and worked with factory managers on scientific time studies. At its most basic level, time studies involve breaking down each job into component parts, timing each element, and rearranging the parts into the most efficient method of working. By counting and calculating, Taylor sought to transform management into a set of calculated and written techniques.

The foundation and principles of scientific management theory are: Employees must be elected based on their skills and abilities related to job; incentives and wages provided to employees should be based on encouraging them and enhancing their output; the leadership within the organization should be one that develops a standard method for doing certain job with the assistance of scientific management theory; there should be attention on eradicating interruptions while planning work; and rule of thumb work methods are replaced with other methods which are based on scientific study of tasks.

Despite the fact that scientific management was considered foundation in the 1930s, it keeps on making noteworthy commitments to management theory today. With the progression of factual techniques utilized as a part of scientific management, quality confirmation and quality control started in the 1930s. Amid the 1950s, scientific management advanced into operations management, operations research, and management robotics. In the 1980 s, add up to quality administration turned out to be broadly famous, and in the 1990s "re-building" turned out to be progressively mainstream. One could truly contend that Taylorism sent the preparation for these expansive and compelling fields we hone today.

Managers who intend to gain relevant and specific results often tend to rely on scientific management theory to guide their operations. The theory however designs and clarifies organizational structures to achieve specific benchmarks and outcomes. Authority is typically delegated to a larger degree than in a bureaucratic system, although departments are designed and staffed with specific purposes in mind. For example, a hospital using scientific management will design the management structure, staffing and number of beds allocated to a postanesthesia care unit to care for a specific number of patients per year. In its approach to managing staff, a scientific-management-driven facility will typically evaluate nurses based on several objective performance indicators including productivity, number of patients seen, days absent and documentation details. 
Scientific Management might be, perhaps better defined as measured functional management. It rests on the principle of applying accurate measurement to present practice, deriving from the results of this measurement and so dividing the work to be done that the standard practice may be carried out by those best fitted to do each part of the work. These being the underlying principles of science of management it is obvious that they are applicable to all fields of activity, and our investigations prove conclusively the hospital can avail itself of this science with greater results than have been obtained in the industries, where the science was first discovered and applied, (Gilbert 2016).

At first glance the hospital offers a particularly difficult field for scientific management, the reason being the difficulty in determining units of measurement. As a matter of fact, the problem of the hospital is less difficult than that of the industries because of the fact that the field contains a larger percentage of highly educated men and women who are therefore better able to appreciate the scientific method applied to their problem (Gilbreth 1915).

Again, hospitals do not have the fierce financial competition for existence that the average business has, that makes it frequently necessary that all changes shall immediately, as well as ultimately be financially profitable. In the average hospital the various departments are not so closely related but that one or more can be subjected to scientific management, and features can be installed without seriously affecting the others.

No one man is fitted to deal with each sort of capacity of hospital management, and that the work load will be better done if it is partitioned or "functionalized" and every division put in the hands of a man particularly fitted and uniquely prepared to take every necessary step of his capacity. There has been an inclination common that a specialist is, in view of his serious restorative preparing, fitted to deal with any and all aspects of hospital management. This inclination is step by step being separated, and it is winding up plainly more for the most part understood that the specialist's preparation in that capacity, not the slightest bit fits him for management or to manage, and that the management of healing centers ought to be given over to master, a prepared supervisor who can alleviate the specialist of much work for which he is not fitted, and for which he has not been prepared and can thus permit him to give his time totally to such function as he can best perform, and get the best outcomes and cause the best number of bliss minutes.

When proper standards are determined, your work must be so divided and assigned that each man in the organization will do that work only which is the highest valued and most efficient work that he is able to do.

\subsubsection{New Public Management Theory (NPM)}

The agitation and movement for the new public management theory began in the late 1970s and early 1980s. Its pioneers began to emerge in the United Kingdom under Prime Minister Margaret Thatcher and in the municipal governments in the U.S that had suffered most heavily from economic recession and tax revolts. Next, the governments of New Zealand and Australia joined the movement. Their successes put NPM administrative reforms on the agendas of most countries. Only later did academics identify the common characteristics of these reforms and organize them under the label of New Public Management (Dunsire, 1995).

The conscious investigation of public administration in the U.S. started in a period when its public administration was in a condition of offensiveness. In the late nineteenth century, the managerial systems in the U.S. that were commanded by the corruption - managerial positions were dispersed to the individuals who added to the triumphant party's discretionary achievement. Managerial work force, along these lines, changed habitually. Inadequacy, wastefulness, and defilement were normal (Weber, 1956).

In response to this defilement, those who sort progress made a development and decided to change governmental issues and organization, squeezing for a more interventionist express, the partition of legislative issues and organization, the legitimacy rule (tenured, nonpartisan, and skillful directors), and sound money related administration. The Progressives accomplished a few prominent victories: a profession benefit, line-thing spending plans, and less political partisanship and corruption (Eisenach,1994) In the 1920s, some practitioners and academics created the science of public administration on the fundamentals of the progressive reform successes-particularly the presupposition of loyal bureaucrats, honest politicians, and the politicsadministration dichotomy. These reformers - the new scientists of public administration - built a theory of organization that they supplemented with the concept of management. These principles were: The principle of 
division of work and specialization; the principle of homogeneity; the principle of unity of command; the principle of hierarchy with respect to the delegation of authority; the principle of accountability; the principle of span of control.

The reformers expected public managers, working within organizational structures built on these principles, to perform the following functions: Planning, Organizing, Staffing, Directing, Coordinating, Reporting and Budgeting, (Gulick, 1937)

Earlier assessments of New Public Management theory notably in Common wealth nations, point to outcomes below expectations. Therefore "The commoditization of deregulated health systems makes them very inefficient and very expensive and it exacerbates inequalities and leads to a deterioration of the quality of care, the World Health Organization (WHO) concluded in its 2008 report on health. Though the way in which the "NHS operates was changed irrevocably by the quasi-market reforms", there were relatively "little measurable changes that could be related unequivocally to the core mechanisms of the quasi-market". A culture of 'classification' or investment designed to impress rather than to provide better outcomes permeated the NHS.

\subsection{Status Quo of Maternal Health Service Delivery at National Level from 2008 to 2015 and Some Existing Policies}

This chapter addresses the status quo of maternal health service delivery at national level from the period of 2008-2015. This chapter also discussed the existing policies for maternal health service delivery in Ghana which includes antenatal care policy, postnatal care policy, and health financing policy and safe motherhood and reproductive health programs in Ghana.

\subsection{Status Quo of Maternal Health Service Delivery at National Level from 2008-2015 High Rate of Maternal Mortality}

The world has witnessed numerous related problems with regards to maternal mortality. Simkhada et.al (2006) states maternal mortality is one of the key indicators of the status of reproductive health care service delivery and utilization but it also can be an indication of women's status in society. They further argue that maternal mortality is currently an issue of concern on the internal health agenda and developing countries tend to suffer the most from such problems.

Ghana as a nation has embarked on several previous ways, methods and policies to curb the high rate of maternal mortality in the country. To a greater extent some of these policies and measures have helped improve the health care system. According to Bliss et al. (2014), over the past 15 years, Ghana has recorded a decrease in maternal mortality rate from 570 deaths per 100,000 live birth in 2000 to 380 deaths per 100,000 live birth in 2013. Thus, despite these progress, however Ghana's Maternal, Neonatal and Child health indicators are worse than those in other countries from 30 deaths per 1,000 live births in 2008 to 32 deaths per 1,000 in 2013. New born deaths account for 40 percent of under-five mortality in Ghana.

\subsubsection{Lack of Infrastructure and External Equipment}

The issue of lack infrastructure and essential equipment has been one of the major problems facing the health system in Ghana and it's largely to be blamed for the high rate of maternal mortality been recorded in the country.

Akoto (2013), states that the availability and efficient use of standard resources in any health facility is a prerequisite indication of ensuring skilled supervised delivery. Several literatures have revealed how essential infrastructure and essential equipment are very vital to improving and curbing maternal mortality. Oye-Ita et al, (2007) emphasized that basic amenities such as water, good sanitation, and sources of power, sterilizers, and hand gloves among others are also essential in preventing infections during deliveries thereby protecting the mother and the new born. For a population of a little short of 23.5 million people, there are only 1,439 health care facilities (IRIN, 5 August 2008). In a study compiled by Van den Boom et al. (2004) stated that access to these facilities distributed across the country with most rural areas lacking basic facilities such as hospitals and clinics as well as doctors and nurses. 


\subsubsection{Maternal Health Disparity}

In as much Ghana as nation has recorded a decline in under-five mortality in recent years from 111 deaths per 1000 live births in 2003 (DHS) to 82/1000 in 2011 (MICS) the overall trend does not put Ghana on track to reach 2015 MDG target of 40 deaths per 1000 live births. A critical look at this trend clearly indicates that much of the improvement in child mortality is occurring in the wealthiest groups of populations, as the gap below shows.

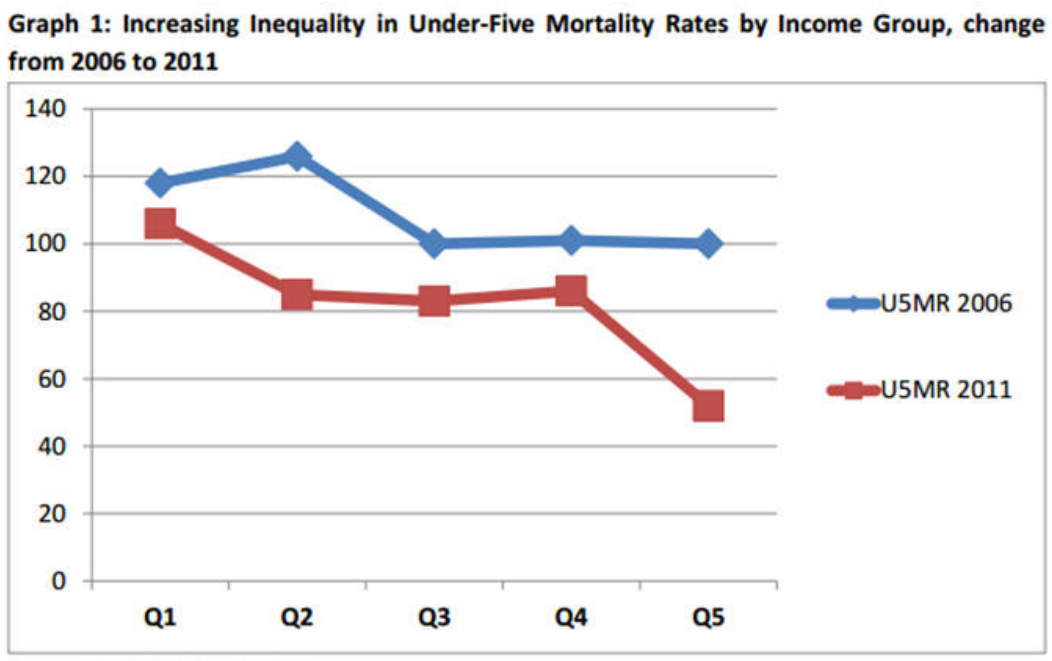

Source: MICS 2006 and 2011

Figure 2: Increasing Inequality in Under-Five Mortality Rates by Income Group, Change from 2006 to 2011 This is to say that there exists some level of disparity in our society. As a result, Ghana is now witnessing a stratification of its society, with the richest pulling far ahead of a large section stagnating in the middle, and the poorest being almost entirely behind.

\subsubsection{Lack of Proper Communication and Transportation}

When it comes to using modern forms of communication, there are still some gaps to be filled in Ghana. This can be narrowed down to the level of disparity that exists in our society. According to a report by UNICEF in (2008), every minute of every day, a woman in the world dies as a result of complications arising during pregnancy and child birth. The majority of these deaths are avoidable and transport has a critical role to play in achieving the Millennium Development Goal (5). According to a study conducted by Asamoah in (2011), "When health management staffs respondents were asked if there was a transport operation system in place, $40 \%$ of them answered in the affirmative whereas $60 \%$ replied in the negative. Similarly, 4 out of $10(40 \%)$ stated that they managed transport resources whilst $60 \%$ of them did not handle any transport resources. Twenty seven percent of health management respondents held that budgets were available for transport management. Conversely, $56.7 \%$ of respondents answered that there were no funds budgeted for transport operations whilst $16.7 \%$ could not tell. The challenges perceived in transport management by health management staff are inadequate vehicles, aged vehicles and poor road networks respectively".

\subsubsection{Inadequate Training and Capacity Building Programmes}

Human resource or employees are the most dynamic and usually the most expensive of all the organization's resources. They need to be supported and nurtured if they are to achieve their full potential, both for themselves and for the organization. Thus, the need to train these health professionals is very essential to help reduce the rate of maternal mortality in Ghana. Ghana as a nation has embarked on several projects to increase training and capacity building both at the community level and for health workers as well. According to the World Health Organization on a study on Ghana, there has been several trainings of mid-level cadres from 2006 with a focus on re-orienting their training and practical scope to meet population health needs. The aim of the plan seeks to address the need for training and continuing medical education for more mid-level health workers is being formulated, building on relevant pilot work. Medical assistants (physician substitutes), for example, were traditionally professional nurses with one additional year training. Midwives are important providers of 
reproductive healthcare services in Ghana. Midwives however have both pre-service training and in-service training. All these forms of training are intended to help make these health workers more professional and help curb the rate of maternal mortality in the country.

\subsection{The Existing Policies for Maternal Health Service Delivery in Ghana}

The governments in Ghana both past and present have introduced and passed out several maternal health policies to help cut the maternal mortality ratio in the country. These policies have in one way or the other helped improve the rate at which women die during child birth.

\subsubsection{Antenatal Care Policy}

According to Dixon (2014) Antenatal care (ANC) can be viewed as contact with a health provider during the time of pregnancy. Thus, antenatal is an important part of the maternal care continuum. Several studies have outlined the benefits of antenatal care to both the mother and the unborn child. Caroli et al. (2001), states that ANC helps in the prevention, detection and treatment of anemia; detection and treatment of hypertensions; treatment of eclampsia (convulsion); prevention of obstructed labor; and screening for and prevention of infection.

Ghana is no exception to some of the African countries that have ensured that ANC and ANC policies are setup to help decrease the high rate of maternal mortality. A study by Agyepong \& Adjei in (2008) stated that Ghana's National Health Insurance Scheme (NHIS) created to abolish user fees and ensure more equitable access to health and as such is one of the very few sub-Saharan African examples of a nationally organized and financed health care scheme. Between 2005 and early 2008, under previous maternal care programs in Ghana ANC was only available with a charge, although delivery was free in public facilities.

Prior to 2008, women needed to pay for antenatal care in Ghana. However, in 2008, the government of Ghana tucked maternal care under the umbrella of the NHIS by creating an exemption for pregnant women from having to pay premium or renewal fees. Therefore, the ANC policy has to a large extent helped women who are not financially strong to still have access to this important maternal care program.

\subsubsection{Post-Natal Care Policy}

According to the World Health Organization (2013) the days and weeks following childbirth - the postnatal period - is a critical phase in the lives of mothers and newborn babies. Major changes occur during this period which determines the well-being of mothers and newborns. The WHO reports that in as much as this period is very vital, critical and important yet it is the most neglected time for the provision of quality services.

Postnatal care (PNC) is considered a priority indicator yet few countries report on it. According to Danso et al. (2014) as cited in Hill et al. (2015), the post-natal care (PNC) policy in Ghana is to promote delivery and immediate post-partum care with a skilled healthcare provider, followed by two visits in the first week of life to counsel on healthy behaviors and assess for danger signs in the mother and child.

\subsubsection{Health Financing Policy}

The health sector is very important and much attention is needed to be given to that sector. Several resolutions have been adopted to help improve the health systems of various countries. According to Zakariah (2015), in May 2005, the fifty-eighth World Health Assembly (WHA) adopted resolution WHA 58.33 on sustainable health financing, universal coverage and social health insurance that urges member states including Ghana to ensure that health financing systems include a method for prepayment of financial contributions for health. It was aimed at sharing risk among the population and avoiding catastrophic health care expenditure and impoverishment of care-seeking individuals.

In their report, Zakariah et al. (2015) stated that "Ghana's estimated population was 24,658,823 in 2010 with a growth rate of $2.5 \%$ and population density increasing from 79 in 2000 to 103 in 2010 . The adult population consisting of people above the age of 18 years stands at 13.6 million, while dependent population, comprising people less than 15 years and above 65 years is pegged at 10.6 million. The total fertility rate is 4.0 and about half the population lives in rural areas. Life expectancy has increased from 58 years to 63.8 years in the last decade". Thus, Ghana adopted a health financing strategy. The vision of the Ghana Health Financing Strategy is moving towards universal health coverage. It is a long journey and the strategy is intended to enable Ghana to 
continuously make progress on the road to universal health coverage (UHC) rather than arrive at the destination by a predetermined date.

\subsubsection{Safe Motherhood and Reproductive Health Programs in Ghana}

The safe motherhood and reproductive health policy was introduced in Ghana in the year 1995. Thus, the policy introduced a wide range of interventions which included antenatal care, labor and delivery care, postnatal care, family planning, prevention and management of unsafe abortions and health education but still maternal mortality rate has not been encouraging in the country over the years and improvements are so slow. The Ghana Reproductive Health Strategic Plan (2007-2011) includes six high-level objectives under its Safe Motherhood Policy, the first of which is to "reduce maternal morbidity and mortality". Included under this high-level objective are five intermediate objectives: Improve access to comprehensive and basic essential obstetric care; improve the capacity of family and community members in home-based, life-saving skills; increase the proportion of deliveries conducted by skilled attendants; increase antenatal care and postnatal care coverage, content, and quality of services; and ensure the availability of comprehensive abortion care services as permitted by law.

\subsection{Case Study of Maternal Health Service Delivery at Korle-Bu Teaching Hospital And Discussion of Findings}

\subsection{The Current Situation of Maternal Health Service Delivery in Korle-Bu}

Korle-Bu Teaching Hospital, the site of this study, is situated in Accra. It is the largest hospital in the country and serves as the teaching hospital for the University of Ghana Medical School. The unit receives referrals from various lower-level facilities within the metropolitan Accra as well as surrounding areas. In most of these facilities the women are cared for almost solely by midwives. Accra city has a population of about 1.8 million people; it also serves as the administrative capital of the Greater Accra Region with a population of about 2.4 million. In addition to Korle-Bu Teaching Hospital, there are seven other government or quasi-government hospitals, seven polyclinics (which are state-owned), 37 registered private maternity homes and 35 private hospitals in the metropolis. The hospital has recorded several cases of maternal deaths. The major indicators of maternal health service delivery include: total maternal death, Live birth, maternal mortality ratio, total deliveries, percentage of death of new borns, number of antenatal and postnatal attendance and so on. Data from the Korle-Bu annual report shows that the obstetric unit of the department of Obstetrics and Gynecology handles about 11,000 deliveries a year; the maternal mortality ratio per 100,000 live births with the year 2011 recorded as high as 1137; the introduction of the Antenatal Policy has had a great impact on the turnout of both Antenatal and postnatal attendance. About 2000 increase in antenatal attendance in 2008 and it was around this same time that the government of Ghana incorporated the maternal care into the NHIS by creating an exemption for pregnant women from having to pay premium or renewal fees. Therefore, the Antenatal Care Policy has to a large extent helped women who are not financially strong to still have access to this vital maternal health care.

\subsubsection{Demographic Characteristics}

Table 4-4 shows the responses given by respondents about their communities from which they come all the way to the Korle-Bu teaching hospital for antenatal care. The findings showed that $10(16.5 \%)$ of the respondents were from Kwabenya, $8(13.3 \%)$ from Cantonment, each $6(10 \%)$ of the respondents are also from Nima, Kotobabi, Adjenkotoku, Mamobi and Adabraka. Each 4(6.7\%) of the respondents are also from the Teshie, Mamprobi and Korle-Bu communities. The widespread of the respondents from different communities indicates that the responses represents the views of most communities and can be used for generalization. 
Table 4-4 Name of your community

\begin{tabular}{|c|c|c|}
\hline Communities & Frequency & Percent \\
\hline Nima & 6 & 10.0 \\
\hline Cantonment & 8 & 13.3 \\
\hline Kotobabi & 6 & 10.0 \\
\hline Adjen Kotoku & 6 & 10.0 \\
\hline Teshie & 4 & 6.7 \\
\hline Manprobi & 4 & 6.7 \\
\hline Mamobi & 6 & 10.0 \\
\hline Kwabenya & 10 & 16.7 \\
\hline Adabraka & 6 & 10.0 \\
\hline Korle-Bu & 4 & 10.0 \\
\hline Total & 60 & 100.0 \\
\hline
\end{tabular}

Source: field data 2017

The level of education of the respondents is indicated in figure 4-1. About 20(33.3\%) of the respondents have some form of primary education. The majority of the respondents $28(46.6 \%)$ as indicated by the finding of this research have obtained secondary education. Whiles $8(13.3 \%)$ and $4(6.7 \%)$ of the respondents have attained tertiary education no basic educational level respectively. The result from figure 4-1 is typical of the Ghanaian setting where girl child education is now gaining root.

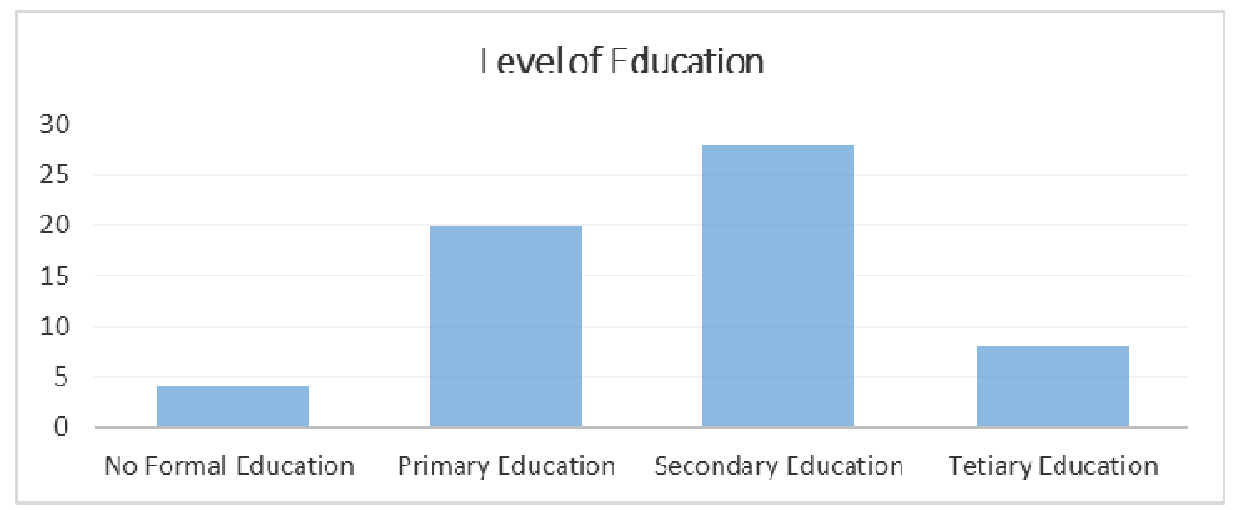

Figure 4-1 Level of Education of Respondents

The majority or the respondents $28(46.7 \%)$ from figure 4-2 were between the ages of 22-32 years. This was followed by $18(30 \%)$ of the respondents who falls within the ages of 33-43 years. It was only 8 and 6 of the respondents who were above the ages of 43 years and less than 21years respectively. The implication of this is that majority of the respondents fall within the adult age and hence has the right knowledge on maternal health service delivery in Ghana to support this study. 


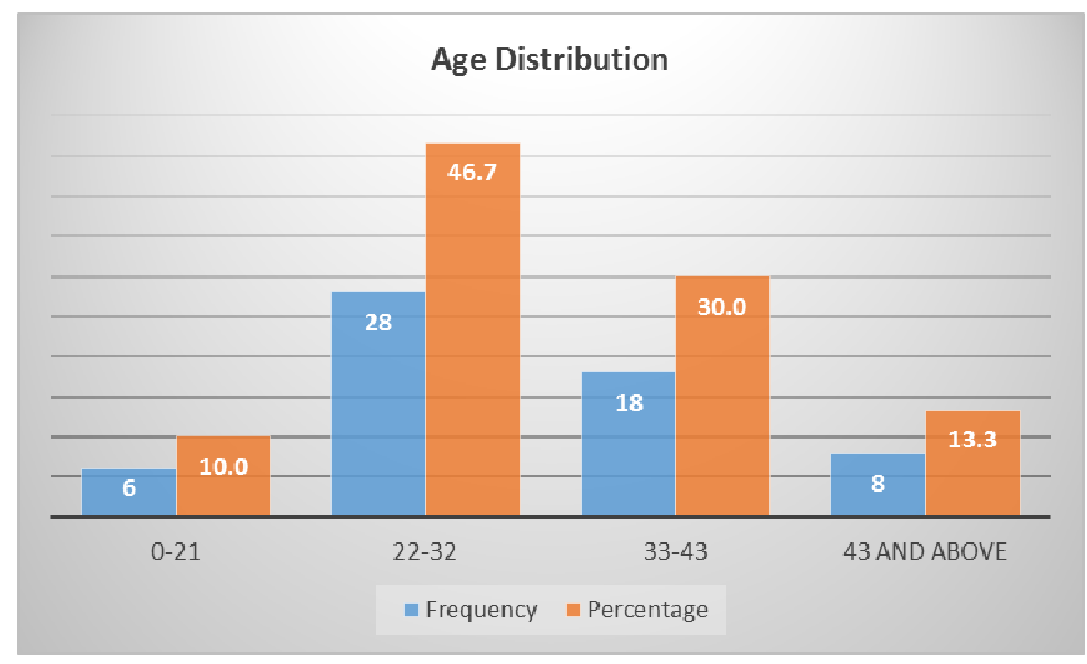

Figure 4-2 Age distribution of Respondents Source: field data 2017

Figure 4-3, depicts the marital status of the respondents. Out of 60 respondents, 28(46.7\%) have indicated that they are married. $24(40 \%)$ of the respondents also stated that they are single, $6(10 \%)$ of the respondents were also found to have divorce/separated from their marriage. However, 2 respondents are widows. This is a clear case that confirms the ages of the respondents since majority of them falls within the young adult age.

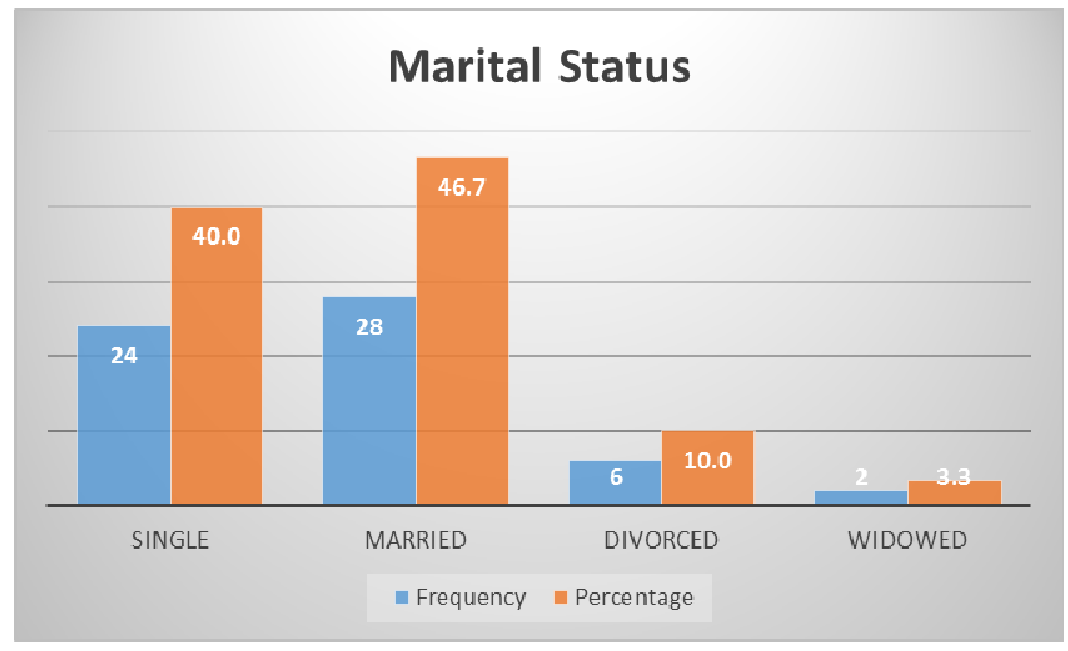

Figure 4-3 Marital Status of Respondents Source: field data 2017

\subsection{Antenatal Care}

Table 4-5 represents the behavioral factors of antenatal experience of pregnant women. A total of 44 women representing $73.3 \%$ responded yes to antenatal care during pregnancy. 16 women representing $26.7 \%$ responded in the negative way. 40 (66.7) of the respondents were told of their expected delivery date, however, $20(33.3 \%)$ where not told of when they will deliver. The last part of this section looks at delivery at public health facilities. 54 representing $90.0 \%$ of the pregnant women interviewed delivered at the public health facility. 6 women did not deliver at the public health facility. From the results, it is clear to agree that majority of pregnant women access the health facility during pregnancy. It is also vivid that majority of the women deliver at the health facility during pregnancy, however it is not $100 \%$ because $10 \%$ of the respondents interviewed do not deliver at the public health facility. 
Table 4-5 Antenatal/ Delivery Experiences

\begin{tabular}{|c|c|c|c|c|c|c|}
\hline \multirow{2}{*}{ Variables } & \multicolumn{2}{|c|}{ Yes } & \multicolumn{2}{|c|}{ No } & \multicolumn{2}{|c|}{ Total } \\
\hline & Freq & $\%$ & Freq & $\%$ & Freq & $\%$ \\
\hline $\begin{array}{l}\text { Did you attend any antenatal care(ANC) during your last } \\
\text { pregnancy }\end{array}$ & 44 & 73.3 & 16 & 26.7 & 60 & 100 \\
\hline $\begin{array}{l}\text { During your antenatal visits were you ever told of the } \\
\text { date on which you were expected to deliver }\end{array}$ & 40 & 66.7 & 20 & 33.3 & 60 & 100 \\
\hline $\begin{array}{l}\text { Did you use public health facilities for your delivery } \\
\text { services }\end{array}$ & 54 & 90.0 & 6 & 10.0 & 60 & 100 \\
\hline
\end{tabular}

Figure 4-4 confirms the responds from the previous table whether the respondents attend antenatal care. The respondent's answers to place of antenatal health care are represented in percentages in the figure below.

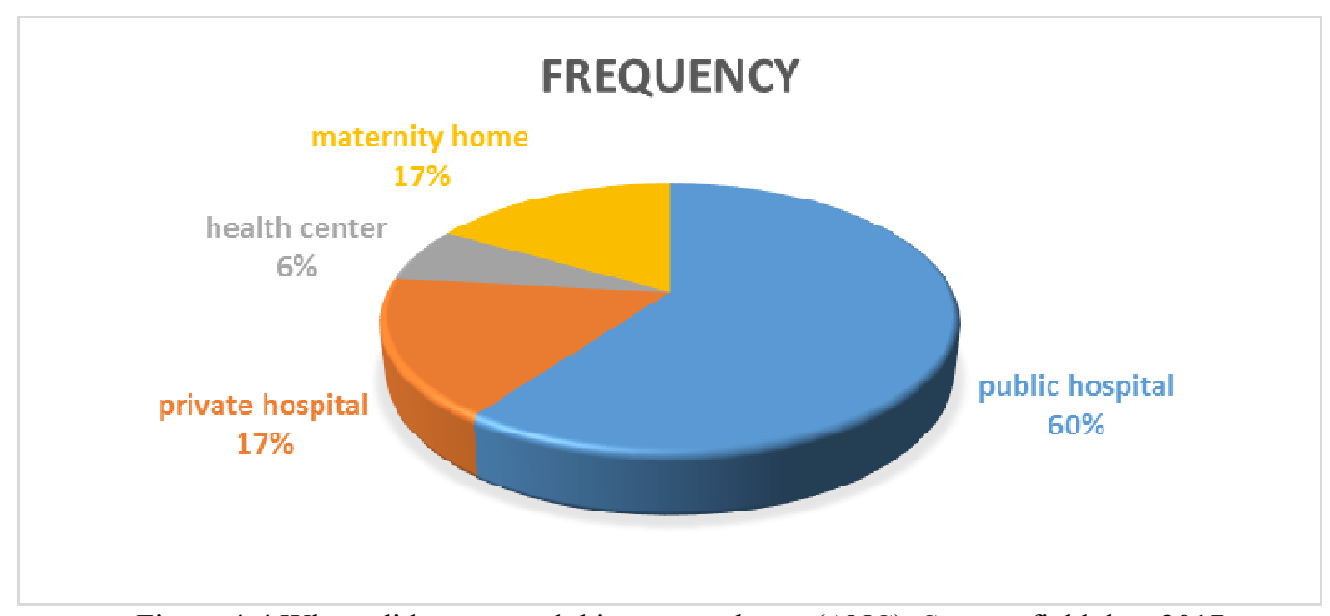

Figure 4-4 Where did you attend this antenatal care (ANC) Source: field data 2017

The study enquired from the respondents their reasons why they go for antenatal care. Table 4-6 represents the responds of the 60 women. A total of 32 respondents go for antenatal to know the health state of the baby or the fetus and this form $53.3 \%$ of the total respondents. 12 women form the second majority of the responds and they go for antenatal care to receive free medicine.

This is because pregnant women are registered free on the National Health Insurance Scheme, therefore if you are a card bearing member you can visit the nearest health facility for antenatal care and also for free medicine where necessary. 6 respondents go for antenatal for medicine and also to know the status of the baby. 4 women out of the total go to register their cards so that they can also deliver or have other services there for free. Another 4 also go for antenatal for all the reasons stated above with only 2 respondents going for injection.

It is evident in the table above that most pregnant women show concern about their babies, therefore they will go for antenatal to check the state of the child and also take free medicine for their health and the health of the child. However, the results show that a little above $50 \%$ of the respondents make use of the facilities. 
Table 4-6 Reasons for going for antenatal care (ANC)

\begin{tabular}{|c|c|c|}
\hline & Frequency & Percent \\
\hline to get registration card & 4 & 3.3 \\
\hline to get injection & 2 & 20.0 \\
\hline to receive free medicine & 32 & 53.3 \\
\hline to know if the baby/fetus is healthy or alive & 6 & 10.0 \\
\hline for medicine and also know the status of the baby & 4 & 6.7 \\
\hline for all the reason above & $\mathbf{6 0}$ & $\mathbf{1 0 0 . 0}$ \\
\hline
\end{tabular}

Source: field data 2017

Table 4-7 shows the frequency of antenatal attendance during the last pregnancy of the respondents. Out of the 60 respondents interviewed 34 of them go for antenatal care more than five times before delivery, 16 out of the total go to antenatal four times before delivery. 4 of the total number of the respondents attend antenatal care twice before their time of delivery. Though the percentage is above 50, the results indicates that the frequency of antenatal care attendance is low.

Table 4-7 Antenatal visits during last pregnancy

\begin{tabular}{|l|c|c|}
\hline Number of Antenatal Visits & Frequency & Percent \\
\hline Twice & 4 & 6.7 \\
three times & 6 & 10.0 \\
\cline { 2 - 3 } four times & 16 & 26.7 \\
\cline { 2 - 3 } five times and above & 34 & 56.7 \\
\cline { 2 - 3 } Total & $\mathbf{6 0}$ & $\mathbf{1 0 0 . 0}$ \\
\cline { 2 - 3 }
\end{tabular}

Source: field data 2017

Table 4-8, respondents were asked to indicate their choice in terms of very

Satisfactory (V-SAT), satisfactory (SAT), dissatisfactory (D-SAT) and very dissatisfactory (V-DIS). When the respondents were asked to share their impressions about the service received from the Korle-Bu teaching hospital, more than half of the respondents 32(53.3\%) said they had a satisfactory impression about the services received from the hospital. $12(20 \%)$ of the respondents also said they are very satisfied whilst $16(26.7 \%)$ of the respondents oppose to the views that the services received were satisfactory.

Again, when the respondents were asked to grade the health staff with the satisfaction of care received, majority of the respondent $32(53.3 \%)$ graded them high by given them satisfactory mark. $14(23.3 \%)$ of the respondents also gave them a very satisfactory grade whilst the other $14(23.3 \%)$ of the respondent said they were dissatisfied with the health staff about the care they received.

The researcher went further by asking the respondent to describe their ward environment. And half of the respondents $30(50 \%)$ indicated that their wards are not satisfactory. However, $26(43.3 \%)$ of the respondents said they are satisfied with the maternal ward environment and $4(6.7 \%)$ of the respondents were very satisfied.

Moreover, most of the respondents 34(56.7\%) saw that the midwife/doctor's relationship with them were satisfactory but $16(26.7 \%)$ disagree to this notion. Most of the respondent $38(63.7 \%)$ also were satisfied with the form of education and counseling given to them about their self and child care before discharged home. Although 10 out of the 60 respondents were very satisfied with the education and counseling given them, another 10 respondents out of the 60 were dissatisfied whilst another 2 respondent out of the 60 said they were 
dissatisfied.

On facilities such as bed, water, wash room, etc. most of the respondents $24(40 \%)$ thought they are not adequate enough at the hospital and should be improved hence they showed a dissatisfaction to that. $2(3.3 \%)$ were very dissatisfied, $18(30 \%)$ were satisfied whilst $16(26.7 \%)$ were very satisfied and thinks that there is no need for an immediate improvement.

When the respondents were asked if the number of midwives/doctors/ nurses that attended to them were satisfactory during labor, 20(33.3\%) of the respondents said yes, 18(30\%) said they were dissatisfied, 14(23.3\%) said they were very satisfactory whilst 8 out of the 60 respondents strongly disagree to this notion by indicating a very dissatisfactory to the question.

Finally, the finding shows that 26(43.3\%) were dissatisfied with the manner in which the midwife/doctor/health staff answered their questions during delivery. However, 20(33.3\%) of the respondents think opposite and indicated that they were satisfied.

From the mother perspective, although the respondents who were satisfied falls below average in some cases, most mother were still satisfied with the quality of health care provided at the Korle-Bu teaching hospital though there is the need for them to improve upon their performance.

Table 4-8 Quality of Health Care from Mother's Perspective

\begin{tabular}{|l|c|c|c|c|c|c|c|c|c|c|}
\hline \multirow{2}{*}{ Variables } & \multicolumn{2}{|c|}{ V-SAT } & \multicolumn{2}{c|}{ SAT } & \multicolumn{2}{c|}{ D. SAT } & \multicolumn{2}{c|}{ V-DIS } & \multicolumn{2}{c|}{ Total } \\
\cline { 2 - 10 } & Freq & $\%$ & Freq & $\%$ & Freq & $\%$ & Freq & $\%$ & Freq & $\%$ \\
\hline $\begin{array}{l}\text { Impressions about the } \\
\text { service received }\end{array}$ & 12 & 20.0 & 32 & 53.3 & 16 & 26.7 & 0 & 0 & 60 & 100 \\
\hline Grade the health staff & 14 & 23.3 & 32 & 53. & 14 & 23.3 & 0 & 0 & 60 & 100 \\
\hline $\begin{array}{l}\text { Describe the maternity ward } \\
\text { environment }\end{array}$ & 4 & 3.3 & 26 & 43.3 & 30 & 50.0 & 0 & 0 & 60 & 100 \\
\hline $\begin{array}{l}\text { Midwife/doctor's } \\
\text { relationship with you }\end{array}$ & 10 & 16.7 & 34 & 56.7 & 16 & 26.7 & 0 & 0 & 60 & 100 \\
\hline $\begin{array}{l}\text { Education/counselling given } \\
\text { to you before discharged } \\
\text { home }\end{array}$ & 5 & 16.7 & 38 & 63.7 & 10 & 16.7 & 2 & 3.3 & 60 & 100 \\
\hline $\begin{array}{l}\text { Facilities such as beds, } \\
\text { water, wash room etc. Are } \\
\text { adequate }\end{array}$ & 8 & 26.7 & 18 & 30.0 & 24 & 40.0 & 2 & 3.3 & 60 & 100 \\
\hline $\begin{array}{l}\text { Number of midwives } \\
\text { /doctors/nurses }\end{array}$ & 14 & 23.3 & 20 & 33.3 & 18 & 30.0 & 8 & 13.3 & 60 & 100 \\
\hline $\begin{array}{l}\text { Midwife/doctor/health staff } \\
\text { answer your question }\end{array}$ & 16 & 20.0 & 20 & 33.3 & 26 & 43.3 & 2 & 3.3 & 60 & 100 \\
\hline
\end{tabular}

Source: field data 2017

Table 4-9 reflects the reasons why the respondents use Korle-Bu teaching hospital as a public health facility maternal health service. The majority of the respondents $32(53.3 \%)$ gave a reason that cost of services are affordable at the hospital that is why they always go there. $10(16.7 \%)$ of the respondents were also of the view that the presence of good doctors and midwives accounts for their use of the public health facility. $4(6.7 \%)$ also indicated that they use the public health facility due to the availability of drugs and other logistics at the hospital. However, the remaining respondents also suggested that it is all the reasons given above that makes them use the public health facility. 
Table 4-9 Why did you use public health facility?

\begin{tabular}{|l|c|c|}
\hline & Frequency & Percent \\
\hline Presence of good doctor/midwife & 10 & 16.7 \\
\hline Cost of services is affordable & 32 & 53.3 \\
\hline Availability of drugs and other logistics & 4 & 6.7 \\
\hline Both cost of transportation and affordable service & 4 & 6.7 \\
\hline All of the above & 8 & 13.3 \\
\hline $\begin{array}{l}\text { Presence of good doctor/midwife and availability other } \\
\text { logistics }\end{array}$ & 2 & 3.3 \\
\hline
\end{tabular}

Source: field data 2017

\subsection{Delivery Care}

When the respondents were asked if they are covered by the health insurance scheme, majority of the respondents $54(90 \%)$ said yes, they are covered. Only $6(10 \%)$ of the respondents said they are not covered. However, when the respondents were asked if the free maternal policy influence their choice of place of delivery, half of the respondents $30(50 \%)$ said yes whilst the other half also indicated no to the same question. Again, the respondents were asked if they incurred additional cost despite the free maternal health policy. 32(53.3\%) said yes whilst the other $47.7 \%$ said they did not incur any additional cost. The respondents who said they incur additional cost despite the free maternal policy indicated that they incur this cost on paying for beds, buying detergents, toiletries, and other medications that are not covered by the national health insurance scheme. The percentages of these findings are shown in table 4-10.

Table 4-10 Delivery care

\begin{tabular}{|l|c|c|c|c|c|c|}
\hline \multirow{2}{*}{ Variables } & \multicolumn{2}{|c|}{ Yes } & \multicolumn{2}{c|}{ No } & \multicolumn{3}{c|}{ Total } \\
\cline { 2 - 8 } & Freq & $\%$ & Freq & $\%$ & Freq & $\%$ \\
\hline \multicolumn{1}{|c|}{ Are you covered by health insurance? } & 54 & 90 & 6 & 10 & 60 & 100 \\
\hline $\begin{array}{l}\text { Did the free maternal policy influence your choice of } \\
\text { place of delivery? }\end{array}$ & 30 & 50 & 30 & 50 & 60 & 100 \\
\hline $\begin{array}{l}\text { Did you incur any additional cost despite the free } \\
\text { maternal health policy? }\end{array}$ & 32 & 53.3 & 28 & 47.7 & 60 & 100 \\
\hline
\end{tabular}

Source: field data 2017

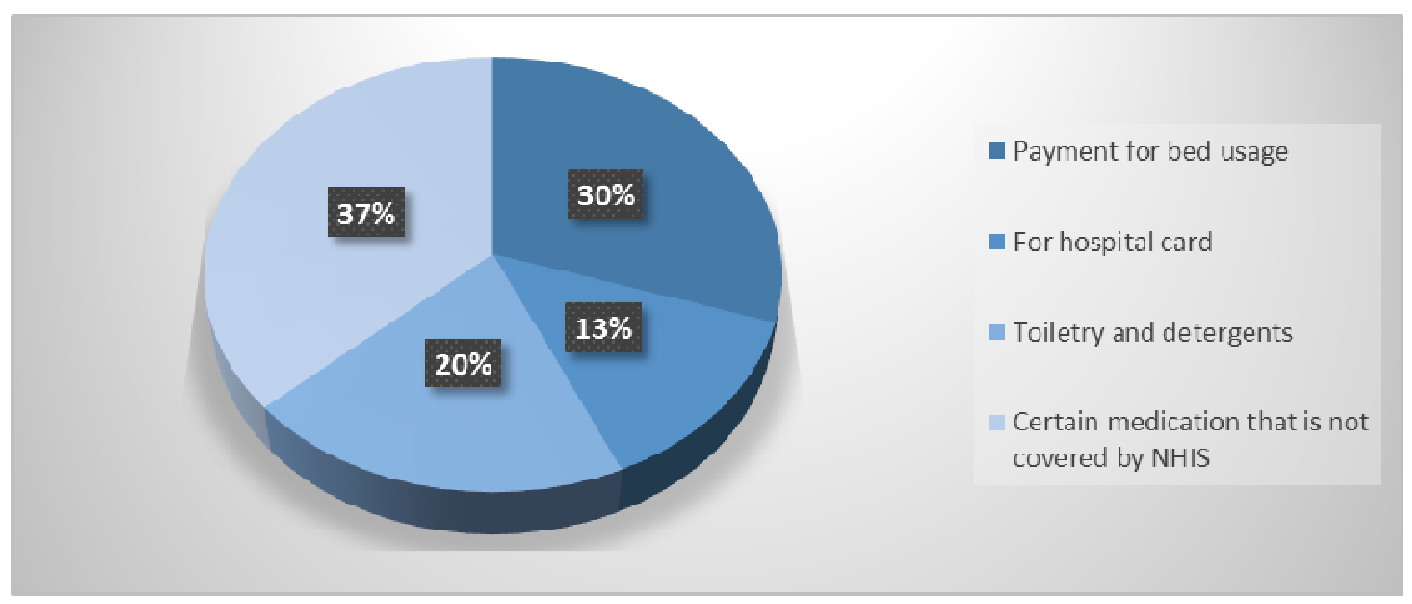

Figure 4-5 If yes, on what did you incur the cost? Source: field data, 2017

When the respondents were asked of the reasons why they choose the Korle-Bu hospital for delivery, majority of the respondents $20(33.3 \%)$ said for safe delivery of baby and mother, $18(30 \%)$ also said for because of the 
professional care that is given by the hospital. However, $4(6.7 \%)$ of the respondents also indicated that they choose the hospital because of both professional and safe delivery of their babies and mothers. Some of the respondents also indicated other reasons such as the friendly nature of the staff at the hospital, and for comfort $8(13.3 \%), 4(6.7 \%)$ respectively. 6 of the respondents also choose both comfort, attendants friendly and safe delivery of babies and mothers as presented in Table 4-11.

Table 4-11 Other reasons for choosing hospital for delivery

\begin{tabular}{|l|c|c|}
\hline & Frequency & Percent \\
\hline For professional care & 18 & 30.0 \\
\hline For safe deliver of baby and mother & 20 & 33.3 \\
\hline For comfort & 4 & 13.3 \\
\hline Attendants friendly & 8 & 6.7 \\
\hline $\begin{array}{l}\text { For both professional care and safe deliver of baby } \\
\text { and mother }\end{array}$ & 4 & 10.0 \\
\hline $\begin{array}{l}\text { For comfort, attendants friendly and safe deliver of } \\
\text { baby and mother }\end{array}$ & 6 & $\mathbf{1 0 0 . 0}$ \\
\hline \multicolumn{1}{c}{ Total } & $\mathbf{6 0}$ & \\
\hline
\end{tabular}

Source: field data 2017

\subsection{Postnatal Care and Consequences of Maternal Mortality}

Table 4-12 is the responses gathered from the 60 respondents on their take on postnatal care. On their response for visit to the hospital after delivery for postnatal care, 56 of the respondents representing $93.3 \%$ said they visited the hospital. Visiting hospital after delivery is very important for the health of both mother and child, however 4 people said they did not go for postnatal care. With regards to the how helpful the service provided was for them, $54(90 \%)$ of the respondents were of the view that it was helpful for them. 6 respondents disagreed with the rest and said it was not helpful to them in any way. On the socio-economic consequence of maternal mortality, $40(66.7 \%)$ of the respondent said yes meaning it has some impact on them. Maternal mortality is one of the serious headaches of the nation's health sector and there are many measures in place to curb this menace. When the issue of the psychological consequence was post before the respondent, $6(10 \%)$ said yes and $54(90 \%)$ said no, maternal mortality has no psychological consequence on them. This is likely to be attributed to the serious work being done to reduce the rampancy of the issue and also the strive to attain a mark on the Millennium Development Goal (MDG).

Table 4-12 Postnatal care after last pregnancy

\begin{tabular}{|c|c|c|c|c|c|c|}
\hline \multirow{2}{*}{ Variables } & \multicolumn{2}{|c|}{ Yes } & \multicolumn{2}{|c|}{ No } & \multicolumn{2}{|c|}{ Total } \\
\hline & Freq & $\%$ & Freq & $\%$ & Freq & $\%$ \\
\hline $\begin{array}{l}\text { Did you visit the hospital for postnatal care after your } \\
\text { delivery }\end{array}$ & 56 & 93.3 & 4 & 6.7 & 60 & 100 \\
\hline Was the postnatal care provided helpful to you & 54 & 90.0 & 6 & 10.0 & 60 & 100 \\
\hline $\begin{array}{l}\text { Does maternal mortality have any socio-economic } \\
\text { consequence on you }\end{array}$ & 40 & 66.7 & 20 & 33.3 & 60 & 100 \\
\hline $\begin{array}{l}\text { Does maternal mortality have any psychological } \\
\text { consequence on you }\end{array}$ & 6 & 10.0 & 54 & 90.0 & 60 & 100 \\
\hline
\end{tabular}

\subsection{Discussion of Findings}

Source: field data 2017

The data gathered from the field by the researcher shows that maternal health service delivery has gained much popularity in the country and much effort is being made most especially in the service delivery to reduce the rate of maternal mortality in Ghana. Despite these efforts the researcher found out that there are still loopholes in the maternal health service delivery in Korle- Bu. Below are some of the factors why there is still an increase in the mortality ratio in Korle-Bu.

a) Behavioral Factors

Self-attitude plays an important role in our daily lives. According to the research conducted 44 of the respondents attended antenatal care during their last pregnancy and 16 of the respondents gave a negative answer. 
Majority of the respondents attended the antenatal care but not a $100 \%$. Some of the respondents also attended antenatal just because it is free and not because of its health benefits. What this results indicates is that, when women develop the attitude of seeking antenatal care, it will help curb the rate of maternal mortality. This is because, seeking antenatal care is a very important during the pregnancy stage of every woman until she delivers and even some weeks after delivery. Thus, women need to understand the benefits of attending antenatal care and how it can help them have a safe delivery. Based on an interview with the respondents, some of them said most at times they don't come on the exact date given to them by the doctors or midwives this is because they feel very strong and they don't see the need to come. Usually, they come when they notice any strange feeling in their system or when they feel sick

\section{b) Quality of Health care received from mothers perspective}

From the data gathered, some of the respondents were dissatisfied with the number of doctors and midwives in the hospital. Some of the respondents were also not satisfied with the education and counseling given to them before they were discharged from the hospital. The researcher also found out that, shortage of health workers has a role to play in poor maternal health service delivery contributing to the high rates of maternal mortality in Ghana. This shortage is due to brain drain which has to do with health workers going abroad in search of greener pastures. This leads to a high rate of doctor to patient ratio forcing one doctor to work for several hours. This hinders the quality of service provided by the doctors since the work load on them is so huge.

\section{c) Financial Factor}

According to the data gathered, 50 respondents constituting $90 \%$ said they went for antenatal because it was free. Another serious cause of maternal mortality in Ghana can be attributed to lack of money. From the research, it is clearly seen that many of the women in Ghana now go for antenatal care during pregnancy but financial problems makes it difficult for them to go for the exact number of antenatal before delivery and also postnatal. Some of the respondents said in the interview conducted to them that sometimes money for transport to the hospital is also another problem to them and sometimes they have to forgo the antenatal because they don't have the money. Again, it is difficult for them to buy the food they need and live in conditions better for their health and nurturing of the fetuses. Again, due to lack of money or poverty, most women are prevented from getting some form of Education that will let them understand their medications, nutrition and how to take proper care of themselves during and after pregnancy. Until the Free maternal Health Policy was introduced, most pregnant women couldn't afford the cash-and-carry system operated by the Ghana health sector and this prevented many of the women from accessing professional antenatal and postnatal care.

\subsection{Analysis on the Ineffectiveness and Inefficiency in Maternal Health Service Delivery in Korle-Bu, Recommendations and Conclusion}

This chapter of the study focused on the ineffectiveness and inefficiencies of the maternal health service delivery and as such discussed the causes of existing problems and analyzed the related policies implementation issues. It also gives necessary recommendations and finally draws a conclusion on the whole study.

\subsection{Analysis of Causes of Existing Problems 6.1.1 Socio-economic Cause}

With rapid population growth in the capital city, the Korle-Bu teaching hospital tends to receive more cases than as expected. Grant AND Yankson (2003) also stated that "since its independence, Accra's population has increased rapidly. In 1957, the city had a population of approximately 190,000”. Thus, the Korle-Bu teaching hospital receives most of the referral cases from other hospitals. This therefore increases the work load on the workers and as such there are limited doctors and nurses to meet the demand resulting in poor quality of maternal health services. On the other hand, economical causes have also led to the ineffectiveness and inefficiencies experienced at the Korle-Bu Teaching Hospital with respect to maternal health service delivery. For instance, in 2014, the hospital through the minister for health wrote a petition to the president describing the financial problems faced by the hospital where he solicited for government to financially support the hospital.

\subsubsection{Political Causes}

The government plays a key role in helping and shaping the health sector by formulating policies and regulating these policies to ensure that there is a safe and effective maternal health system. Change of government affects 
the progress of various health institutions in the country. Several women have been reported to have died during childbirth because they could not make it to emergency obstetric care due to strikes, restricted movement of vehicles and other reasons emanating from change of government. According to Fusheini et al (2012) political threats include political interferences in the day to-day management of the affairs and appointment of the Chief Executive Officer (CEO) by the sitting president of Ghana, which could breed political interference. Such activities breed misunderstanding and as such disturb the smooth delivery of services.

\subsubsection{Analysis of Related Policies Implementation}

The maternal health policy in Ghana has related policies that helps it to function effectively. To achieve Goal 5 of the MDGs, the Government of Ghana introduced the free maternal health service system to break financial barriers of access to maternal care services. In spite of this, facility-based deliveries continue to be low due partly to poor quality of antenatal care that prevents pregnant women from giving birth in hospitals.

Distance to the health facilities generally influence women perception of antenatal care quality but the relative odds of reporting quality of care as good attenuated with proximity to the health facility. Five factors (pleasant interaction with providers, privacy during consultation, attentiveness of providers, adequate facilities and availability of drugs) emerged as statistically significant in explaining antenatal care quality.

According to Alhassan et. al (2010), a report by the Ghana Health Service (GHS) "indicated that the implementation of the NHIS contributed to increased pressure on health infrastructure and staff. According to the GHS annual report, this increased pressure resulted in longer waiting times, illegal charging of fees and nonadherence to standard professional practices by health workers."

Several studies have indicated and outlined several shortcomings of the implementation of the NHIS which was introduced as a way of improving the health system in Ghana. The Millennium Development Goals 4 and 5 which is to reduce child mortality and improve maternal health still remains an important health challenge in Ghana. Ensuring all women give birth with a skilled birth attendant and have access to emergency obstetric care is accepted as the most crucial intervention for reducing maternal and newborn deaths. In Ghana, skilled attendance at delivery is unequally distributed. In 2003-2008 among the poorest $20 \%$ of women, $24 \%$ delivered with a health professional compared to $95 \%$ among the richest $20 \%$. Many factors influences the rate of skilled birth attendance including the cost of care, which especially for emergency obstetric care can be catastrophic for households. To address this issue, several countries in sub-Saharan Africa including Ghana have abolished fees for delivery care. Susie Dzakpasu (2012)

\subsection{Conclusion and Recommendations}

The issue of delivering quality maternal health services is very vital to help curb the rate of maternal mortality. The world Health Organization and other departments and organizations have developed several strategies that will help reduce the rate of maternal mortality especially in developing countries. Most of these strategies have yield positive results but still there exist certain gaps that needs to be breached to help curb the rate of maternal mortality.

This paper however concludes that, the MDG5 plan in Korle-Bu Teaching has not fully been achieved. There exist several short falls in the service delivery of the hospital that requires much attention if the MDG 5 has to be fully achieved. The findings of this research work can help us draw the conclusion that the Free Maternal Healthcare Policy implemented in 2008 by the Government of Ghana to curtail and curb the high rate of maternal mortality in the country has had an impact on reducing maternal mortality thus some of the problems identified in this research for the ineffectiveness of the policy and recommendations made, must be addressed and implemented by the concerned agencies so as to help the country achieve its MDG 5.

Also, this paper concludes that, the level of satisfaction received through the services provided by the nurses and doctors at the hospital did not fully meet the satisfactory level of the various respondents that were interviewed. Patients who were dissatisfied with some of the services rendered to them by staffs at the hospital discussed how such treatments discouraged them and created some level of hindrance to the services delivered to them.

Finally, this paper concludes that maternal health service delivery at the Korle-Bu Teaching Hospital still needs much improvements. Services like educating pregnant women and providing support to them still needs much 
attention and as such nurses and doctors need much regular training session and orientation about how to handle patients with care and respect. Therefore, to enhance effective and efficient maternal health services delivery, the Korle- $\mathrm{Bu}$ teaching hospital has to amend some of its strategies and methods of delivering services to these pregnant women.

\subsection{Recommendations}

\subsubsection{Public education}

There is the need for government to invest more in educating the public about the policy, its aims, and objectives and why it was established. Most of the respondents who were interviewed face to face expressed their dissatisfaction when they were asked to pay some amount of money when they arrived at the hospital. Most of them claimed they were misinformed and they thought the policy clearly specified that everything is free. This created a whole lot of complications since some of them had to wait for long hours before they could be attended to.

\subsubsection{Developing a merit pay system}

The maternal health policy should develop a system that will attribute pay to performance. The policy alone cannot achieve excellent results without doctors, nurses and other stake holders involved playing their various roles effectively. The findings of the study revealed that in as much as most of the respondents expressed satisfaction about the services they received from doctors and nurses, some respondents still expressed alarming dissatisfaction about the way they were treated. This study however recommends that the policy should create a system where good and hardworking doctors, nurses and other stakeholders will be rewarded or paid based on merits, thus they should attribute or link pay to merits or develop a merit pay system. This will help put all workers on their toes and work to achieve results rather than having the idea that whether they work or not they will earn equal salaries.

\subsubsection{Infrastructural development}

The maternal health policy alone cannot help reduce maternal mortality without taking other equally important factors into considerations. Thus, despite the introduction of the maternal health policy, there is the need to improve upon the infrastructure of most of the hospitals across the nation. Therefore, improvement in infrastructural development will help reduce maternal mortality. Infrastructural development might not only limit us to buildings and structures. Other important things that can be considered include drugs, beds and among other equipment that will make service delivery at the hospital very effective and efficient.

\subsubsection{Self-Funding}

In as much as the free maternal health policy was introduced to make maternal health services free, it is highly recommended by the researcher that individuals who are pregnant or individual women keep some money to enable them fund some of the bills that they might incur during childbirth or through the pregnancy stage to the delivery stage.

The findings of this research work showed that most women were dissatisfied or were caught by surprise when they were asked to make certain payments at the hospital to cover some bills. Thus, this research work recommends that most women should create a room for self-funding to enable them to meet some bills that will not be covered by the policy.

\subsubsection{Capacity Building Programmes Perspective}

Lastly, this research work recommends that the government should invest more in capacity building programmes to enable all the parties involved improve their skills and knowledge needed to do their jobs effectively. This capacity building programmes should not only be focused on educating women but also doctors, midwives, nurses and other stakeholders involved in the policy formulation. It is only through such regular programmes that certain issues that are not clearly defined and stated in the policy can be cleared.

\section{REFERENCES}

[1] L. Lannes. An Analysis of Health Service Delivery Performance in Rwanda[J]. 2015, 3, (16).

[2] World Health Organisation Report. Why Do Many Women Still Die In Pregnancy Or Childbirth [R]. New York: World Health Organization, 2010,18.

[3] K. Mills. Trends in Maternal Mortality: 1990 to 2013 [R]. New York: United Nations Organization,2014, 23.

[4] R. Biritwum. Promoting And Monitoring Safe Motherhood in Ghana [J]. Ghana Medical Journal, 2003,40 (3). 
[5] W. Leni. Common Constraints and Incentive Problems in Service Delivery [J]. Overseas Development Institute, 2012, 9(12-15).

[6] L. Sambo. Country Cooperation Strategy at a Glance [R]. Swaziland: World Health Organization (WHO), $2014,36$.

[7] Y. Yamikeh. Ghana's Maternal Mortality Rates Still High [N]. The Statesman Ghana's Oldest Mainstream Newspaper, $2008,7$.

[8] World Health Organization Report [R]. Geneva: UNICEF, Postnatal Care of the Mother and Newborn,1996, 33.

[9] S. K. Gumanga, A. Munkaila, and H. Malechi, Social Demographic Characteristics of Women With Pelvic Organ Prolapse at The Tamale Teaching Hospital-Ghana [J]. 2014, 48 (4).

[10] W. L. Neuman. Social Research Methods: Qualitative and Quantitative Approache [R]England: Pearson Education,2011, 9.

[11] M. Ahmed. Access And Utilisation Of Free Maternal Health Services In The Savelugu-Nanton District In The Northern Region [D]. University of Cape Coast, 2011, 7-8.

[12] World Health Organization Report [R]. Factsheet: Millennium Development Goal 5. New York: World Health Organization, $2008,19$.

[13] V. Bertalanffy General System Theory: Foundations, Development, Applications [D]. University of Alberta-Canada, 1968,25-24.

[14] M. Hagman. Maternal Mortality : Gender and Access to Health Services - The Case of Ghana[J]. Ghana Medical Journal, 2013, 9(173211).

[15] C. Moser. Gender Planning and Development: Theory, Practice and Training [R]. Routledge, London,1993, 25.

[16] D. Allen. Developing Effective Mentoring Relationships: Strategies From the Mentor's Viewpoint [J]. The Career Development Quarterly, 199, 48 (59-73).

[17] P. Stromquist. Educating Women: The Political Economy of Patriarchal States [J]. International Studies in Sociology of Education, 1991, 1 (10-19).

[18] C. E Okojie. Gender Inequalities of Health in The Third World [J]. Social Science and Medicine, 1994, 39(9).

[19] C.A Varga. How Gender Roles Influence Sexual and Reproductive Health Among South African Adolescents. [J] Science and Medicine, 2003, 30(3).

[20] C. Bunch. Women's Rights As Human Rights: Toward a Re-vision of Human Rights [J]. Human Rights Quarterly, $1990,12(4), 48-52$. [23] W. Sesay. Female Bodies: Gender Inequalities, Vulnerability, HIV and AIDS in Kenya [J]. Advancing Women in Leadership Journal, 2010, 30(17), 1-44.

[24] J. Erdman. Harm Reduction, Human Rights and Access to Information on Safer Abortion [J]. International Journal of Gynecology and Obstetrics, 2012, 118(1), 83-86.

[25] R. Gordon. Girls Cannot Think as Boys Do: Socializing Children Through The Zimbabwean School System [J]. Gender \& Development , 1998, 6(2), 53-58.

[26] F. Leach. (1998). Gender, education and Training: an International Perspective. [J] Gender \& Development, 1998, 6(2), 9-18.

[27] M. Dunne. Gender Violence In Schools In The Developing World [J]. Gender and Education , 2006, 18(1), 75-98

[28] N. Kabeer. Gender Equality and Women's Empowerment: A Critical Analysis of The Third Millennium Development Goal 1 [J].

Gender and Development, 2005, 13(1), 13-24.

[29][30] F. Gilbreth. Scientific Management in the Hospital [J].Business and Economic History, 1995:18(4-9)

[31] A. Dunsire. Administrative Theory In The 1980s: A Viewpoint [J]. Journal of Public Administration., 1995, 73(1), 17-40.

[32] E. Eiesenach. Improving Maternal , Neonatal, and Child Health in Ghana [J]. Ghana Medical Journal, $2014,32(2), 15-21$.

[33] B. Moon. The Millennium Development Goals Report [R]. New York: United Nations Organization, $2008,21$.

[34] J. Ansong. Hospital Based Maternity Care in Ghana- Findings of a Confidential Enquiry into Maternity Deaths [J]. Ghana Medical Journal September, 2007: 41(130)

[35] K. Senah. Maternal Mortality in Ghana: The Other Side [J]. African E-Journals Project: Institute of Africa Studies, 2003, 45 (55-61).

[36] http://www.ghanahealthservice.org/maternal-health.php

[37] J. Witter. Health policy and the Delivery of Health care: Introduction and Private Health care Plan Case Study [R]. New: York ,Johns Hopkins Bloomberg School of Private Health, 2009, 30.

[38] E. Asante Ameyaw. An Assessment Of The Effect Of The Free Maternal Care Policy On The Utilisation Of Maternal Care Services In The New Juaben Municipality [D]. Kwame Nkrumah University of Science and Technology-Kumasi, 2011,10-15

[39 ] I. Thaver \& A. Bhutta. Poverty and Ill-Health: Challenges, Initiatives and Issues in Pakistan [D]. Khan University, $2006,1-6$. 